4

\title{
Printability and mechanical performance of biomedical PDMS-PEEK composites developed for material extrusion
}

\author{
James A. Smith ${ }^{1}$, Simin Li $^{1}$, Elisa Mele ${ }^{2}$, Athanasios Goulas ${ }^{1}$, Daniel Engstrøm ${ }^{1}$, Vadim V. \\ Silberschmidt ${ }^{1}$ \\ ${ }^{1}$ Wolfson School of Mechanical, Electrical and Manufacturing Engineering, Loughborough University, \\ Loughborough, Leicestershire, LE11 3TU, UK \\ ${ }^{2}$ Department of Materials, Loughborough University, Loughborough, Leicestershire, LE11 3TU, UK
}

\section{Abstract}

Polydimethylsiloxane (PDMS) materials are widely adopted in the manufacture of facial prostheses, lab-on-chip devices and scaffolds for soft-tissue engineering applications; however, their processing by additive manufacturing (AM) has proved challenging. Liquid silicone rubbers (LSRs) are favoured for their high shape fidelity when cast, but their low viscosity and surface tension often prevent self-support, post-extrusion. Poly(ether) ether ketone (PEEK) particle reinforcement through interfacial bonding has proven to enhance key properties of PDMS, expanding their end-use functionality. Still, the impact of such particles on the printability of LSR-PDMS is not explored. In this study, for the first time, solvent-free biocompatible PDMS-PEEK composites (up to 30 wt.\% PEEK) were successfully characterised for material extrusion (ME) printing. Rheological analysis confirmed shearthinning of all PDMS-PEEK composites under applied load (within the tolerances of the printer) and dominant storage moduli at rest (i.e. prints can self-support), considered highly desirable for ME-based printing. Attained rheological datasets were used to guide initial printability studies, which revealed finer track fidelity with rising fractional content of PEEK, at comparable print speed and displacement values. Composites with higher PEEK content demonstrated significant increases in Shore A hardness and stiffness (in tension and compression) in bulk form. Last but not least, enhanced shape fidelity (thanks to PEEK reinforcement) and geometrical autonomy further expanded the manufacturing freedom of PDMS, whereby infill density could be controlled in order to increase the range of mechanical performance, 
1 previously unachievable with conventional casting fabrication. Fundamentally, this could lead

2 to the manufacture of bespoke spatially graded multi-material structures and devices that

3 could be used to replicate the heterogenous properties of soft human tissues and in other

4 advanced material applications.

\section{Graphical abstract}

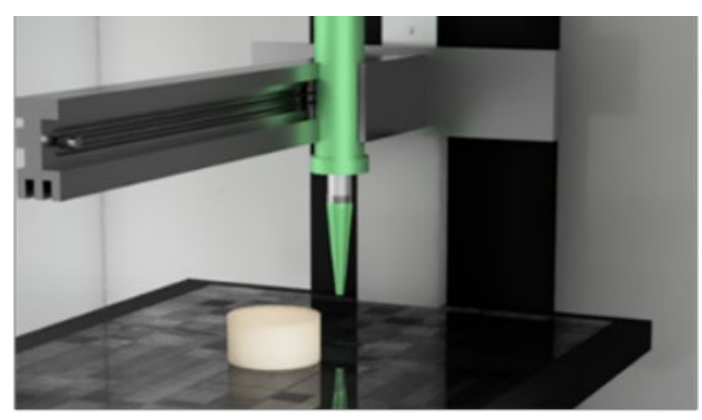

PEEK content (Wt.\%)

\begin{tabular}{llll}
0 & 10 & 20 & 30 \\
\hline
\end{tabular}

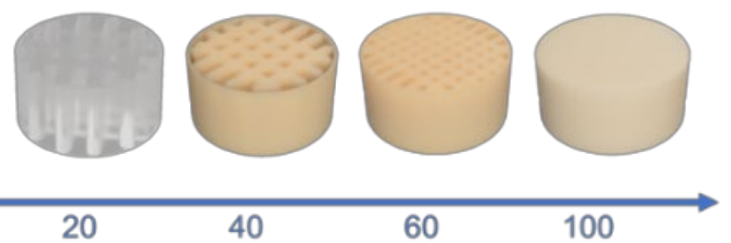

Spatial infill (\%)
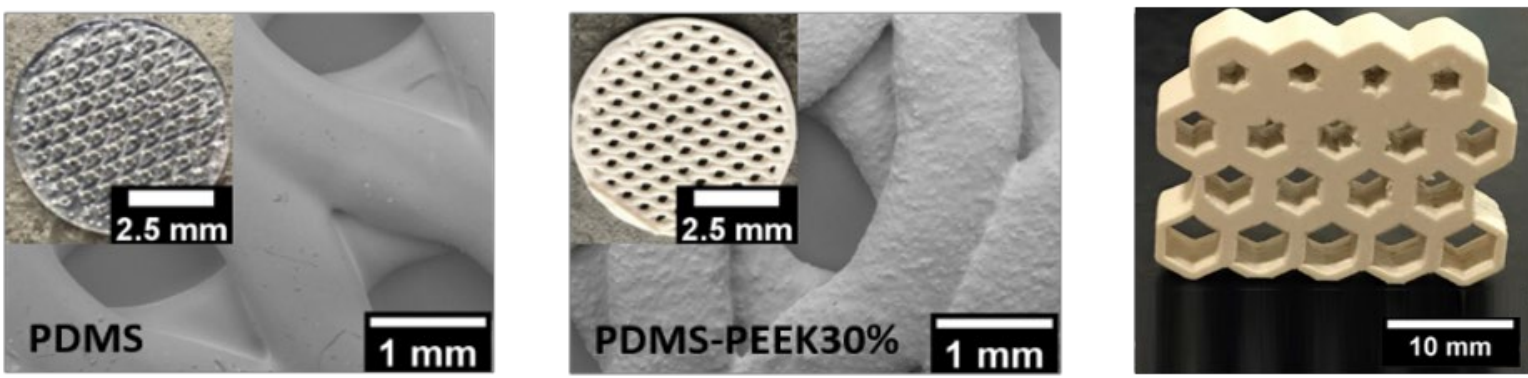

6

7 Keywords: PDMS; PEEK; polymer composite; additive manufacturing; material extrusion. 


\section{1. Introduction}

2 Polydimethylsiloxane (PDMS) is one of the most widely adopted polymers for biomedical 3 application, where its use stretches across a range of structures and devices including scaffolds for soft-tissue engineering, facial prosthetics and lab-on-chip-devices [1-3]. This is explained by PDMS's mechanical flexibility, biocompatibility, chemical resistance, durability, gas permeability, optical transparency and mouldability $[1,4,5]$. Hence, attempts to process PDMS and other silicone-based materials by additive manufacturing (AM) have risen significantly over the past decade, with varying levels of success [2,3,6-14].

For instance, Hinton et al. adopted a freeform embedding technique to extrude PDMS into a series of microparticulate polymer-gel support baths [8]. Key characteristics of the support baths included their low yield point $(\sim 50 \mathrm{~Pa})$ and thixotropic recovery, enabling the syringe of a material extrusion (ME) 3D printer to glide through the polymer medium and selectively deposit PDMS, held in place by the support-gel. Additionally, the printed components could be removed from the supporting gel by non-toxic chemicals (phosphate-buffered saline, PBS), thanks to immiscibility between PDMS and the polymer support bath. When evaluating their tensile performance, printed PDMS specimens recorded significantly lower levels of stiffness $(\sim 0.90 \pm 0.20 \mathrm{MPa})$ relative to their cast variants $(\sim 1.60 \pm 0.30 \mathrm{MPa})$, which is generally considered disadvantageous [15].

O'Bryan et al. developed their own in-house micro-organogels (combination of di- and tri-block co-polymer microparticles mixed at various ratios in mineral oil) to support viscous Liquid Silicone Rubber (LSR) [9]. In principle, the micro-organogels behaved similarly to those developed by Hinton et al., i.e. gel yielded upon the application of applied stress (from syringe nozzle) and recovered upon its removal. However, addition of highly packed micro-particles into the mineral oil increased its viscosity beyond previously achieved levels, enabling the gel to tightly hold the extruded silicone in place. As a result, specimens presented a smoother, more complete appearance compared to previous work [8]. Whilst the use of micro-organogel support baths appears to be a viable strategy to process LSR's by AM, their adoption adds 
1 post-processing complexity e.g. utilization of toxic organic-solvents/surfactants to remove

2 support-bath material from cured PDMS. Consequently, this could hinder the implementation

3 of this method in the manufacture of PDMS components for biomedical applications.

4 Zheng et al. formulated their own low-viscosity LSR inks with the addition of chain extenders

5 and 2,4,6-trimethylbenzoylphenyl phosphinate (TPO-L) photoinitiators [16]. By incrementing

6 the ratio of TPO-L from $0.1-10 \mathrm{~mol} \%$, full cure was decreased from 10 minutes to less than 20

7 seconds upon exposure to ultraviolet (UV) light. Consequently, LSR had the ability to selfsupport (post-extrusion) as demonstrated in prints of hollow hemispherical structures.

9 However, beyond overhang angles of $70^{\circ}$, material sag was observed, leading to reduced levels of shape fidelity. From a biomedical perspective, the use of photoinitiators raises safety concerns, whereby a lack of sufficient cure can result in loose monomers migrating throughout the body, causing oxidative stress and negative tissue response [17-19].

Ozbolot et al. developed a series of custom PDMS inks to be directly processed by ME onto glass substrates [2]. Proprietary ink formulations comprised of high-viscosity (542 Pa.s) PDMS adhesive and a low-viscosity (5.1 Pa.s) PDMS (Sylgard 184) elastomer, known for its biocompatibility. It was demonstrated that the mechanical properties of these inks could be fine-tuned by manipulating blending ratios. Notably, 9:1 and 8:2 inks printed longitudinally outperformed their cast counterparts, recording elastic moduli values of $2.82 \pm 0.28 \mathrm{MPa}$ and 3.16 $\pm 0.25 \mathrm{MPa}$ vs. $1.90 \pm 0.34 \mathrm{MPa}$ and $1.67 \pm 0.52 \mathrm{MPa}$, respectively. Ultimate tensile strength (UTS) values for cast 9:1 and 8:2 inks were recorded as 3.74 $\pm 1.46 \mathrm{MPa}$ and $3.28 \pm 1.90 \mathrm{MPa}$, increasing to $9.34 \pm 1.26 \mathrm{MPa}$ and $10.9 \pm 4.28 \mathrm{MPa}$ for longitudinally printed specimens. Notably, such rises are uncommon for 3D printed components, which often exhibit reduced levels of mechanical performance [20]. Importantly, when exposing metastatic breast cancer cells to the surface of both printed and cast PDMS ink specimens, it was determined that cells favoured the printed topology (exhibiting increases in cell surface area and nuclei number). By contrast, cells cultured on cast inks formed aggregates, failing to spread across the elastomers surface [20]. 
1 Print speed and resolution are typically considered limiting factors of ME. Consequently, Liravi

2 and Toyserkani developed a hybrid AM machine combining both pneumatic ME (external 3 contour of build) and piezoelectric-pneumatic material jetting (MJ) (internal fill) technologies to 4 improve these factors [14]. Once print parameters were optimised, square shapes of silicone were built to evaluate their surface resolution. Along the $x$-axis, extruded specimens recorded average surface deviations of 3-4 $\mu \mathrm{m}$, whilst their jetted counterparts demonstrated increased levels of waviness $(8-10 \mu \mathrm{m})$ and the presence of voids within their structures. Both tensile and tear properties were explored, however these were performed on moulded PDMS sheets opposed to those printed, hence requiring further investigation. Although the hybrid configuration has the potential capacity to reduce printer build time, further work is necessary to eliminate both surface defects and mechanical anisotropy, leading to high-resolution parts with spatial grading and tailored porosity.

Bhattacharjee et al. set out to fabricate PDMS-based materials that could mimic the properties of medical-grade PDMS, with stereolithography (SLA) [10]. Principally, the technology uses UV light to react with photoinitiators contained in liquid monomer, selectively cross-linking and building the desired geometry layer-by-layer. Hence, TPO-L was selected for its ability to solubilise in PDMS and to absorb wavelengths in the spectral range of $385-400 \mathrm{~nm}$. Evaluation of biocompatibility demonstrated that printed specimens had a significantly negative effect on cell (CHO-K1) viability (82\% reduction) over a 72-hour period. Consequently, solvent extraction was required to remove traces of uncured monomer, prior to matching viability values of the control. Such results further demonstrate the drawbacks of using photoinitiatorbased chemistry to develop materials for medical use.

Compositing through particle reinforcement is a proven method to enhance intrinsic properties of polymer matrices [15]. Recently, our group introduced polydisperse poly(ether) ether ketone (PEEK) particle fractional volumes into the matrix of PDMS to form functionally graded materials (FGMs) through a conventional (non-AM) stepwise layering approach, without the need of toxic solvents [21]. Significant rises in mechanical stiffness $(287 \%$ and $189 \%$ for 
1 PDMS containing 20 wt. \% PEEK in tension and compression, respectively), as well as

2 comparable levels of biocompatibility (healthy cell morphology) were witnessed in

3 conventionally moulded samples, supporting their application for heterogeneous soft-tissue

4 applications.

5 Coupling the PDMS-PEEK composite with the benefits of AM technologies, including the

6 fabrication of complex geometries and the ability to functionally grade through components to

7 alter the mechanical, thermal and chemical properties of the build, could lead to the

8 development of patient-specific implants, devices and prosthetics that better match the tissues

9 they aim to replace. Until now, it was unknown whether PDMS-PEEK composites were indeed

10 processable with ME technologies and if so, the effect of spatial grading on their mechanical

11 performance. In this study, rheological characterization is undertaken to elucidate the flow

12 behaviour of each composite (up to 30 wt.\% PEEK), revealing the ability to self-support at rest

13 and shear-thin within the tolerances of ME technology (without any photo initiator-based chemistry or toxic solvents, promoting the biomedical adoption). The rheological insight is then applied to printability studies in order to optimise machine parameters, before printing bulk and spatially graded test pieces. Finally, test pieces are mechanically loaded to determine Shore A hardness, tensile and compressive behaviour, in order to assess the full performance range of the developed composite elastomers. 


\section{2. Materials and Methods}

2 To successfully print polymers by ME, a thorough understanding of their physio-chemical

3 behaviour before, during and after manufacture is essential. Hence, a variety of studies were

4 performed to assess pre-cure (rheology, printability and curing parameters) and post-cure

5 (mechanical performance of both bulk and spatially graded specimens) PDMS-PEEK

6 composites. All tests in this and other sections were performed in ambient laboratory

7 conditions of $20^{\circ} \mathrm{C}$ and $55 \% \mathrm{RH}$, unless specified.

8 The raw material stock used in the study was acquired commercially from the following

9 suppliers: two-part medical-grade LSR polydimethylsiloxane $\left(\mathrm{M}_{\mathrm{w}} \sim 95,000 \mathrm{~g} / \mathrm{mol}\right.$, MED4930,

10 NuSil) from Polymer Systems Technology Ltd. (High Wycombe, U.K.) and 20 $\mu$ m poly(ether)

11 ether ketone powder $\left(\mathrm{M}_{\mathrm{W}} \sim 7800 \mathrm{~g} / \mathrm{mol}\right.$ VESTAKEEP ${ }^{\circ} 2000$ UFP 20, previously characterised

12 in [21]) from Evonik Industries $\mathrm{GmbH}$ (Marl, DEU). Materials were used without further

13 purification. PDMS part A (dimethyl siloxane pre-polymer) and B (dimethylhydrogensiloxy +

14 platinum catalyst cross-linker) were combined through a twin-screw nozzle. To produce

15 PDMS-PEEK composites, PEEK was introduced into the PDMS matrix at 10 wt.\% (PDMS-

16 PEEK10\%), 20 wt.\% (PDMS-PEEK20\%) and 30 wt.\% (PDMS-PEEK30\%) and manually

17 stirred until uniform dispersion was achieved, whereby aggregates of PEEK particles were not

18 visually identifiable from the bulk matrix, producing a homogenous tan-coloured system.

19 PDMS pastes containing 40 wt.\% PEEK were explored; however, these were overly brittle due

20 to matrix saturation and removed from the study.

\section{$21 \quad 2.1$ Rheology}

22 Pre-cure PDMS-PEEK samples were individually characterised using a Physica MCR 101

23 rheometer, (Anton Paar, Ostfildern-Scharnhausen, DEU). To determine the impact of PEEK

24 particle fractions on the flow behaviour of PDMS, both shear viscosity $(\eta)$ and shear stress $(\tau)$

25 sweeps were performed as a function of shear rate $(\dot{\gamma})$ between $0.01-100 \mathrm{~s}^{-1}$ (typically

26 experienced during extrusion-based processing). A three-phase study was performed on

27 PDMS and PDMS-PEEK composites to determine their thixotropic behaviour. Viscosity 
1 measurements were recorded across three distinct phases of shear rate over time: the first

2 phase at $\dot{\gamma}=0.1 \mathrm{~s}^{-1}$ held for $25 \mathrm{~s}$; the second at $\dot{\gamma}=100 \mathrm{~s}^{-1}$ held for $50 \mathrm{~s}$; and the third at $\dot{\gamma}=0.1$

$3 \mathrm{~s}^{-1}$ for $250 \mathrm{~s}$. Shear rate sweeps were carried out to identify the phase dominance, the linear

4 viscoelastic region (LVE) and the yield stress (flow point) of PDMS-PEEK composites. The

5 storage (G') and loss moduli (G') of PDMS-PEEK composites were in the same range. $N=5$

6 samples per composite material per test were used.

$7 \quad 2.2$ Additive manufacturing

$8 \quad 2.2 .1$ Printability window

9 To establish the printability of PDMS-PEEK, each material was loaded into $50 \mathrm{ml}$ syringe barrels (EMO-25 extruded, Hyrel3D, Norcross, Atlanta, U.S.) tipped with smooth-flow luer lock nozzles $(\varnothing 840 \mu \mathrm{m}$, QuantX) and then attached to the printer (System $30 \mathrm{M}$, Hyrel3D, Norcross, Atlanta, U.S.). Linear tracks were chosen to characterise each material due to their simplistic dimensions and ease of repeatability relative to input variables (print speed and positive displacement). Tracks were printed from $1.25-10.00 \mathrm{~mm} / \mathrm{s}$ and at positive displacement values of $100-300$ pulses $(P) / \mu$ l onto a borosilicate glass substrate. To minimise inertial effects and stabilise material flow in the barrel, a four-track perimeter was deposited prior to printing tracks for assessment. $\mathrm{N}=5$ tracks per combined variable (material composition, print speed and positive displacement), with 5 individual regions analysed with an optical microscope (Promotech Materials, Zeiss, Cambridge, U.K.) per sample (track), were produced. Bulk specimens (with 100\% infill) were designed using CAD software (Fusion 360, Autodesk) with dimensions according to ASTM standards: (i) tensile dog-bone specimens with the gauge length $25.0 \mathrm{~mm}$, width $6.0 \mathrm{~mm}$ and thickness $3.2 \mathrm{~mm}$ (type IV of ASTM D638-14) and (ii) compressive cylindrical ones with diameter $20 \mathrm{~mm}$ and thickness $10 \mathrm{~mm}$ (ASTM D39516). For spatially graded components, infill density was varied from $20-60 \%$ through the printer's proprietary software (Repetel, Hyrel3D, USA). Mechanical pieces were then sliced into 2D layers (SLIC3R) of $420 \mu \mathrm{m}$ (half the nozzle

$\varnothing)$ and converted to G-Code. All 
1 mechanical test pieces were fabricated in a recti-linear fashion with each sequential layer

2 being altered by $45^{\circ}$ (tension) and $90^{\circ}$ (compression) in a crosshatch arrangement.

$3 \quad 2.2 .2$ Effect of curing on dimensional accuracy

4 To assess the effect of holding temperature on cure rate and geometrical accuracy, PDMS-

5 PEEK cylindrical samples $(\varnothing 14.5 \mathrm{~mm}$ and thickness $6.25 \mathrm{~mm}$ ) were held in an oven (WF200,

6 Lenton, U.K.) at $70^{\circ} \mathrm{C}$ (same as in previously study) and $150^{\circ} \mathrm{C}$ (in-line with manufacturer's

7 recommendation) until full cure, before being removed and left to cool at RT [21]. Specimen

8 dimensions were then measured with Vernier calliper (Digital $150 \mathrm{~mm}$, Duratool, U.K.).

9 Sections of spatially graded PDMS-PEEK composites were removed by scalpel and placed 10 onto aluminium stubs (Agar Scientific, Stansted, U.K.) pre-installed with carbon tabs (Agar 11 Scientific, U.K.) and sputter-coated for $60 \mathrm{~s}$ with Au-Pd (80:20). Topology and cross-sectional 12 area of virgin specimens were then captured with scanning electron microscopy (SEM) 13 (TM3030, Hitachi, Düsseldorf, DEU) and then assessed by ImageJ software to determine strut feature size of the specimens. $\mathrm{N}=5$ samples per composite material were employed.

\subsection{Mechanical performance}

\subsubsection{Shore A hardness}

To assess the resistance of PDMS-PEEK to plastic deformation (hardness), cylindrical specimens $\left(\varnothing 20 \mathrm{~mm}\right.$; thickness $10 \mathrm{~mm}$ ) were loaded beneath the $35^{\circ}$ cone-shaped springloaded- indenter of a Shore A hardness machine (H17A Macro IRHD, Wallace, U.K.) in line with ASTM D2240-15 standard. A primary load was applied to the printed component for calibration purposes, before being removed and then applied once more. A maximum indention force of $8.05 \mathrm{~N}$, at a dwell-time of $3 \mathrm{~s}$ was used to collect each reading. All measurements were taken away from the specimen's edge $(\sim 2.5 x$ the length of the indenter's diameter), in line with ASTM D2240-15. $\mathrm{N}=5$, and all samples were left $24 \mathrm{~h}$ in the lab to acclimatise. 
$1 \quad$ 2.3.2 Tension and compression

2 PDMS and PDMS-PEEK specimens were individually loaded into uniaxial testing systems, 3 (Instron 3344 [tension] and Instron 3363 [compression], High Wycombe, U.K.) equipped with

$4 \quad 1 \mathrm{kN}$ and $50 \mathrm{kN}$ load cells, respectively. A quasi-static strain rate of $0.001 \mathrm{~s}^{-1}$ was applied to 5 both sample types and failure was recognised as a drop in load by $5 \%$. The elastic moduli of 6 all samples were calculated within the linear region of the stress-strain curve between 0.1-0.2 $7 \quad$ strain. $\mathrm{N}=5$ samples per material.

$8 \quad 2.3 .3$ Statistical analysis

9 The mechanical performance of PDMS-PEEK composites was statistically assessed using 10 software package (SPSS 24, IBM, New York, U.S). 1X4 one-way analysis of variance 11 (ANOVA) was performed to assess mechanical datasets that met parametric assumptions. 12 Where significant observations were met, Tukey post-hoc analysis was used to determine 13 differences between sample groups. Where parametric assumptions were violated (i.e. normal 14 distribution), Kruskal-Wallis $\mathrm{H}$ test was carried out to determine statistical significance in 15 accordance with Bonferroni correction to account for incremental type-1 error. All data are 16 reported as mean \pm standard deviation. Significance was assumed at $p<0.05$. 


\section{3. Results and Discussion}

\section{$2 \quad 3.1$ Rheology}

3 At the lowest evaluated shear rate $\left(0.01 \mathrm{~s}^{-1}\right)$, PDMS recorded a viscosity of $550 \mathrm{~Pa} \cdot \mathrm{s}$, which

4 rose to $860 \mathrm{~Pa} \cdot \mathrm{s}$ (PDMS-PEEK10\%), $1860 \mathrm{~Pa} \cdot \mathrm{s}$ (PDMS-PEEK20\%) and $3900 \mathrm{~Pa} \cdot \mathrm{s}$ (PDMS-

5 PEEK30\%) (Fig. 1). Between 0.01 and $0.2 \mathrm{~s}^{-1}$, flow curves of both PDMS and PDMS-

6 PEEK10\% exhibited upper Newtonian plateau, indicating that material viscosity was

7 independent of shear rate [22]. However, for PDMS-PEEK 20\%, the upper plateau was

8 reduced to $0.01-0.03 \mathrm{~s}^{-1}$ and vanished for PDMS-PEEK30\%. Beyond the Newtonian plateau,

9 PDMS-PEEK composites demonstrated shear-thinning (pseudoplastic) behaviour. As shear 10 rates rose $\left(0.1 \mathrm{~s}^{-1}\right)$, all materials exhibited a drop in viscosity to $540 \mathrm{~Pa} \cdot \mathrm{s}$ for PDMS, $870 \mathrm{~Pa} \cdot \mathrm{s}$

11 for PDMS-PEEK10\%, 1660 Pa.s for PDMS-PEEK20\% and 3100 Pa.s for PDMS-PEEK30\%.

12 The power-law region for all PDMS-PEEK composites was identified between shear rates 0.7-

$134.7 \mathrm{~s}^{-1}$. At $1 \mathrm{~s}^{-1}$, viscosity values further declined to $340 \mathrm{~Pa} \cdot \mathrm{s}$ (PDMS), $410 \mathrm{~Pa} \cdot \mathrm{s}$ (PDMS14 PEEK10\%), $520 \mathrm{~Pa} \cdot \mathrm{S}$ (PDMS-PEEK20\%) and $740 \mathrm{~Pa} \cdot \mathrm{s}$ (PDMS-PEEK30\%). As shear rates increased from 10 to $100 \mathrm{~s}^{-1}$, composites with higher PEEK loading demonstrated reductions in Newtonian plateau in agreement with the literature [23-26]. The power-law index $(n)$ for the PDMS-PEEK composites was achieved by fitting the power-law region of the flow curve to the Ostwald-de-Waele power law:

$$
\tau=k \dot{\gamma}^{n}
$$

where $\tau$ is the shear stress, $k$ is the consistency index, $\dot{\gamma}$ is the shear rate and $n$ is the power-law index describing various behaviours: (i) shear-thinning when $0<n<1$; (ii) Newtonian when $n=1$; (iii) shear-thickening when $n>1[27,28]$. It was determined that the shear-thinning behaviour declined proportionally with the increasing PEEK fraction, where $n$ was recorded as 0.35 (PDMS), 0.39 (PDMS-PEEK10\%), 0.42 (PDMS-PEEK20\%) and 0.46 


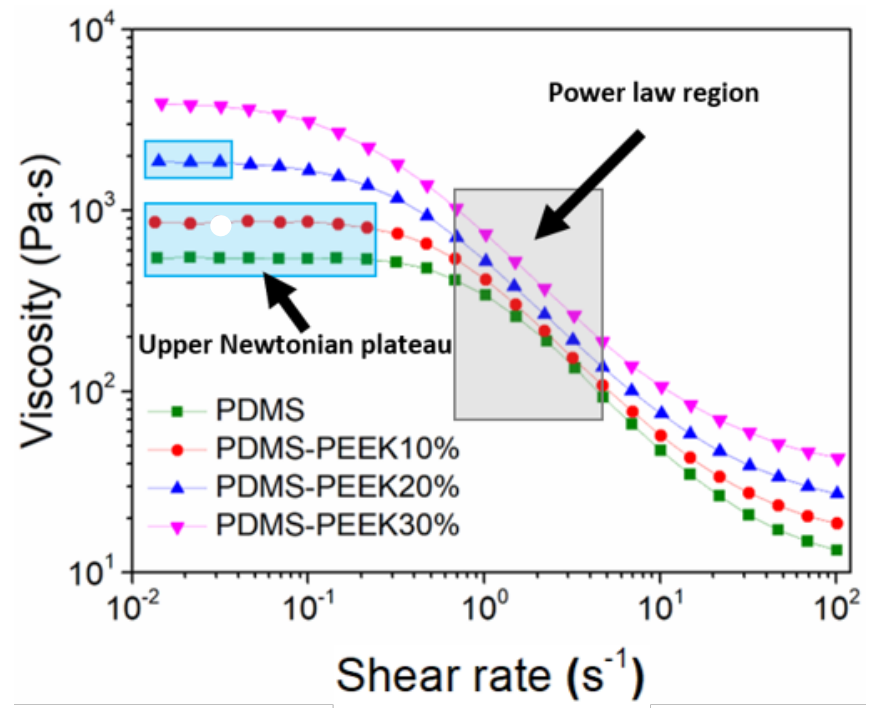

Fig. 1. Rheological characterization; effect of shear rate on viscosity for PDMS and PDMS-PEEK composites. Upper Newtonian plateau and power region highlighted.

3 As consequence of rising PEEK fractional volume, the viscosity of PDMS rose at comparative 4 shear rates, due to incremental increases in internal friction [23,29-31]. In its un-reinforced 5 state, the siloxane chains of PDMS have the capacity to flow and deform freely at relatively 6 low shear stress (Fig. 2 a), hence, recording comparatively lower material viscosities than 7 those containing PEEK $[32,33]$. Upon the introduction of PEEK, previously free-flowing 8 siloxane chains must change their flow stream around the solid particles (Figs. 2 b-d) [32].

9 Siloxane chains at the PEEK interface experienced significant rises in internal friction resulting in chain restriction $[23,29,30,34,35]$. As PEEK fractional loading increased, distances between adjacent particles declined, causing greater resistive forces on the siloxane chains and hindering their movement (Figs. 2 b-d) [23]. Furthermore, rises in attractive forces and internal friction (with increasing solid content) resulted in greater energy dissipation, in turn stiffening the matrix material $[23,36]$. Consequently, higher shear stresses are required to overcome the internal resistive forces (particle-particle interactions that predominate the matrix) to induce material flow $[23,37]$. Furthermore, all polymer composites showed a significant reduction in viscosity. This phenomenon can be attributed to the molecular restructuring of PDMS, whereby entangled siloxane chains, untangle, stretch and align parallel to the flow paths at 
1 higher shear rates (Fig. 2e) [32]. Such phenomena are also true for PEEK composite

2 materials, however additional particle rearrangement would occur [38]. Also, secondary forces

3 could cause particles to flocculate, overcoming repulsive forces between similarly charged

4 particles and form loosely bound aggregates throughout the matrix [32,35]. Subsequently,

5 homogeneity of the blend, the number of PEEK particles bound to siloxane chains and the

6 internal friction between material interfaces decline, permitting material to flow with reduced

7 viscosity [39].
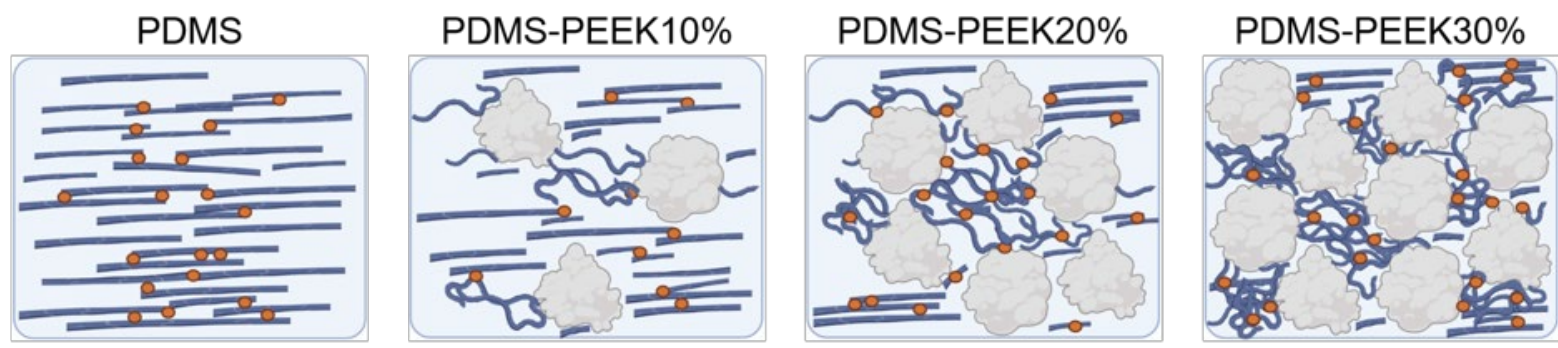

(a)

(b)

(c)

(d)

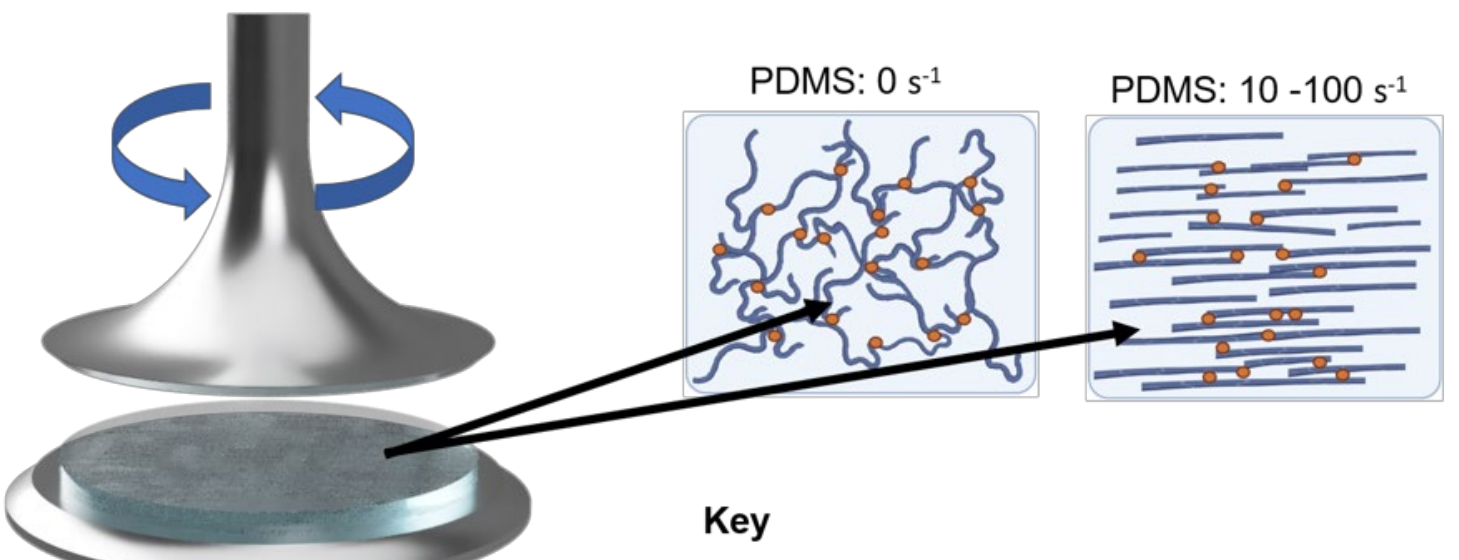

(e)

Pre-polymer siloxane chain

Cross-linker

PEEK powder

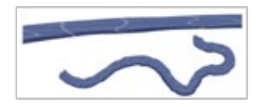

O

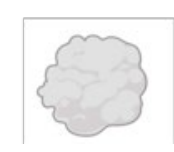

Fig. 2. Behavior of siloxane chains at increasing shear rate and rising PEEK content; (a) PDMS, (b) PDMSPEEK10\%, (c) PDMS-PEEK20\% and (d) PDMS-PEEK30\%. (e) Schematic: siloxane chain structure at rest and at 
1 Three-phase thixotropic studies were performed to determine the impact of PEEK fractions on

2 structural rebuild (level of material breakdown indicated by a drop in viscosity) and 3 dependence of subsequent physio-chemical recovery on shear rate and holding time (Fig. 3)

$4 \quad[38,39]$. Obtaining recovery rates for each polymer composite is essential for fabrication of ME components, whereby the initial print layer must be completely rebuilt prior to the deposition of the subsequent one (reducing void formation and geometrical inaccuracies) [40,41]. As observed in the flow behaviour study (Fig. 1), the viscosity of PDMS rose with increasing PEEK content; however, the respective values were significantly higher. This phenomenon was attributed to both the material ageing and cross-linking processes. A low shear rate $\left(0.1 \mathrm{~s}^{-1}\right)$ was selected to imitate the flow behaviour of materials at rest/pre-print (Phase 1), recording viscosities of $2710 \pm 50 \mathrm{~Pa} \cdot \mathrm{S}$ (PDMS), $4515 \pm 40 \mathrm{~Pa} \cdot \mathrm{s}$ (PDMS-PEEK10\%), 9430 $\pm 10 \mathrm{~Pa} \cdot \mathrm{S}$ (PDMS-PEEK20\%) and 10600 $\pm 110 \mathrm{~Pa} \cdot \mathrm{s}$ (PDMS-PEEK30\%). As shear rate was increased to $100 \mathrm{~s}^{-1}$ (mimicking the upper boundaries of extrusion-based printing), all composites experienced structural break-down, represented by a significant drop in viscosity readings (Phase 2). To assess thixotropic rebuild, the shear rate was then reduced back to $0.1 \mathrm{~s}^{-1}$ (Phase 3), replicating materials post-print. Upon declining shear rate, all PDMS-based composites began to rebuild their structures, confirming that PDMS-PEEK materials are thixotropic. The full recovery was recorded at 18.0 s (PDMS and PDMS-PEEK10\%), $32.5 \mathrm{~s}$ (PDMS-PEEK20\%) and 39.0 s (PDMS-PEEK30\%), indicating the time differences required prior to depositing subsequent layers when extruded at high shear rate $\left(100 \mathrm{~s}^{-1}\right)$. Correlation between the rising PEEK content and extended recovery times can be linked to both the rearrangement of PDMS's molecular structure and the formation of PEEK particles flocs, as discussed $[38,39]$. At high shear rate $\left(100 \mathrm{~s}^{-1}\right)$, the weakly bonded network was destroyed, reducing the size of formed flocs and the viscosity of the composite system $[32,38,39]$. As shear rates dropped, perikinetic motion drove particle re-flocculation through the formation of weak attractive forces $[39,42,43]$. As particle motion reduced, the composite network structurally reorganised until it finally matched its resting form (between 18.0-39.0 s) $[39,42,43]$. Higher thixotropic recovery rates associated with higher particle fraction can be 
1 attributed to greater numbers of rotating particles within the system and the need for longer 2 periods of time to reach a complete standstill $[38,44,45]$.

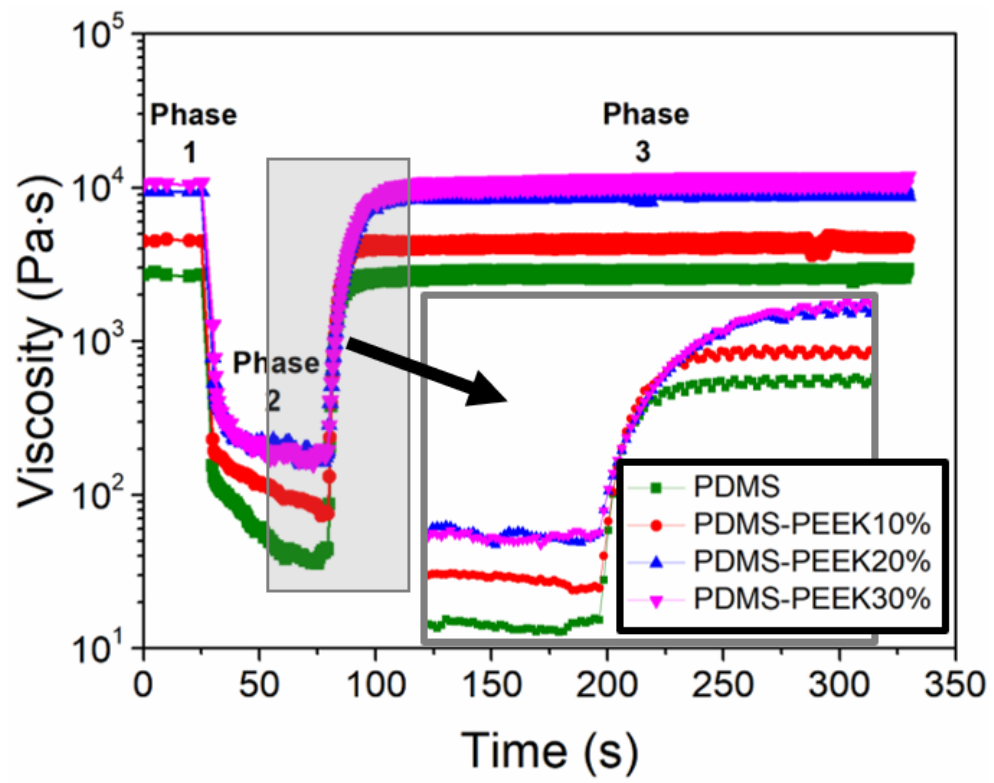

Fig. 3. Rheological characterization; three-phase thixotropy-evolution of viscosity over time at shear-rate changes for PDMS and PDMS-PEEK composites (insert shows thixotropic rebuild zoomed in).

4 Identifying the yield point and phase dominance (i.e. materials ability to self-support at any 5 given shear rate) of PDMS-PEEK composites is essential in determining whether the 6 composite material can be extruded and retain shape upon deposition $[3,37,46]$. Hence, strain sweeps of PDMS-PEEK variants were undertaken (Fig. 4). At resting shear rates $\left(0.1 \mathrm{~s}^{-1}\right)$, all materials had a dominant storage modulus $\left(G^{\prime}\right)$, which rose with increasing PEEK fractional volumes. Similarly, the loss modulus (G") of PDMS increased with PEEK loading. As shear rates grew to $1 \mathrm{~s}^{-1}$, all PDMS-PEEK composites retained dominant $\mathrm{G}$; however, it was significantly lower than that at smaller shear rates. G" also demonstrated reductions with increasing shear rate; however, their values were closer to their G' counterparts. Noticeably, composites with higher PEEK fractional content had the lowest difference between G' and G' values. G" of PDMS-PEEK30\% became dominant at shear rates of $0.78 \mathrm{~s}^{-1}$, indicating the end of the viscoelastic linear viscoelastic (LVE) region. Continuing this trend, PDMS-PEEK20\% was next to reach phase cross-over (yield) at $1.15 \mathrm{~s}^{-1}$ followed by PDMS-PEEK10\% $\left(1.91 \mathrm{~s}^{-1}\right)$ and PDMS $\left(2.74 \mathrm{~s}^{-1}\right)$, suggesting that the materials were capable to yield at low shear rates. 
1 Above these shear rates, the PDMS-PEEK composites become processable with ME.

2 Furthermore, all materials had the ability to retain the shape of their builds thanks to intrinsic

3 elastic dominance at their rest. Such behaviour was previously unachievable for the PDMS-

4 PEEK composites fabricated from LSR encapsulant [21]. The reason for this was the lower

5 level of $M_{w}(\sim 60,000 \mathrm{~g} / \mathrm{mol})$ attributed to the two-part encapsulant, resulting in the reduced

6 levels of chain entanglement upon combination and, hence, an intrinsically lower viscosity,

7 compared to that of the medical-grade LSR $(\sim 95,000 \mathrm{~g} / \mathrm{mol})$ used in this study.
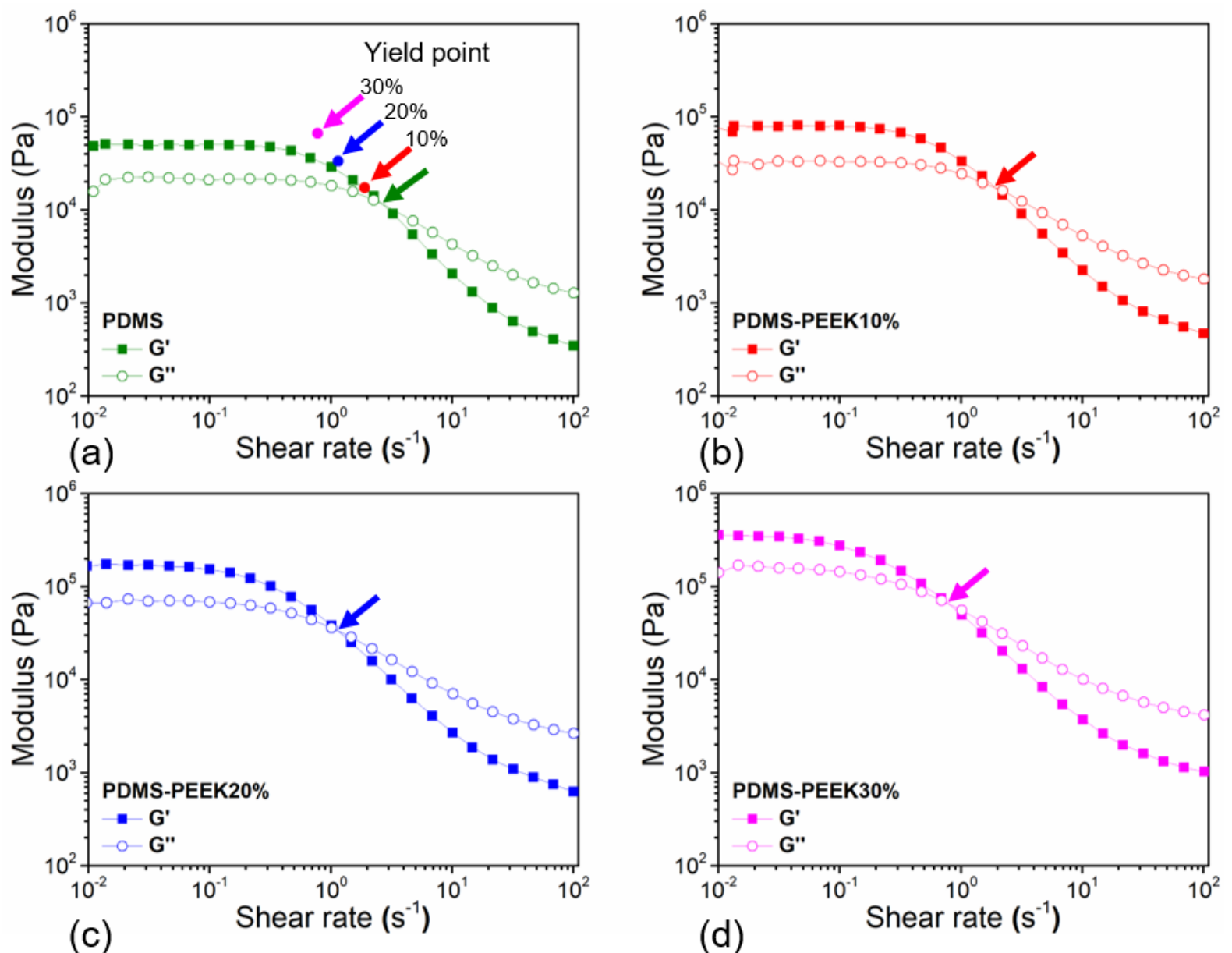

Fig. 4. Rheological characterization; strain rate sweep for (a) PDMS (coloured arrows and dots represent yield points of PDMS-PEEK composites relative to one another), (b) PDMS-PEEK10\%, (c) PDMS-PEEK20\%, and (d) 


\section{3.2.1 Printability window}

3 To assess the printability of PDMS-PEEK composites, tracks were extruded at print speeds of

4 1.25-10.00 mm/s at positive displacement values of 100-300 pulses (P)/ $\mu \mathrm{l}$ (Fig. 5).

5 Combinations of increased PEEK fraction, reductions in positive displacement and speed led

6 to a general decrease in track width. The PDMS control was successfully deposited under all

7 testing conditions, demonstrating a decline in track width with descending positive

8 displacement and higher nozzle speeds; i.e. widths reduced by $115 \%$ (at $250 \mathrm{P} / \mu \mathrm{l}$ ), $156 \%$ (at

$9200 \mathrm{P} / \mu \mathrm{l}$ ), $229 \%$ (at $150 \mathrm{P} / \mu \mathrm{l}$ ) and $297 \%$ (at $100 \mathrm{P} / \mu \mathrm{l}$ ) relative to those printed at $300 \mathrm{P} / \mu \mathrm{l}$ at

$1010 \mathrm{~mm} / \mathrm{s}$. Retaining positive levels of displacement while reducing the print speed by half,

11 resulted in increased track widths; these rises were recorded as 22\% (at $100 \mathrm{P} / \mu \mathrm{l}$ ), 109\% (at $150 \mathrm{P} / \mu \mathrm{l}), 154 \%$ (at $200 \mathrm{P} / \mu \mathrm{l}$ ), 188\% (at $250 \mathrm{P} / \mu \mathrm{l}$ ) and 194\% (at $300 \mathrm{P} / \mu \mathrm{l})$.

As PEEK content increased, the track dimensions further declined at comparable printing parameters. For instance, the PDMS track widths decreased $11 \%$ (PDMS-PEEK10\%), 28\% (PDMS-PEEK20\%) and 47\% (PDMS-PEEK30\%) at a positive displacement of $250 \mathrm{P} / \mu \mathrm{l}$ and print speed of $2.5 \mathrm{~mm} / \mathrm{s}$. Notably, rising PEEK fractional volume also reduced the printability window of PDMS, for instance, 10 wt. \% PEEK content prevented successful deposition below $150 \mathrm{P} / \mu \mathrm{l}$ irrespective of print speed; similarly, PDMS-PEEK $20 \%$ and PDMS-PEEK30\% specimens could only be deposited at $200 \mathrm{P} / \mu \mathrm{l}$ and $250 \mathrm{P} / \mu \mathrm{l}$, respectively, and above at 1.25 $\mathrm{mm} / \mathrm{s}$. As print speed exceeded $2.5 \mathrm{~mm} / \mathrm{s}$, PDMS-PEEK $30 \%$ could not be processed regardless of positive displacement. For PDMS-PEEK20\%, tracks could only be successfully deposited from $150 \mathrm{P} / \mu \mathrm{l}$ when the print speed was increased to $5 \mathrm{~mm} / \mathrm{s}$ and $10 \mathrm{~mm} / \mathrm{s}$. Reasons for such trends was the rise in material viscosity, requiring significantly higher load to overcome the intrinsic properties of PEEK solids and their interactions with PDMS's matrix to initiate flow, i.e. rises in internal friction causing siloxane chain restriction $[23,29,30,34,35]$. Furthermore, as consequence of higher reinforcement ratio, the matrix became ever more saturated [3]. As a result, lower numbers of unbound 'sticky' siloxane chains were present in 
1 the volume, hindering the composites' ability to adhere to the build platform with increasing 2 print speeds $[37,48]$.

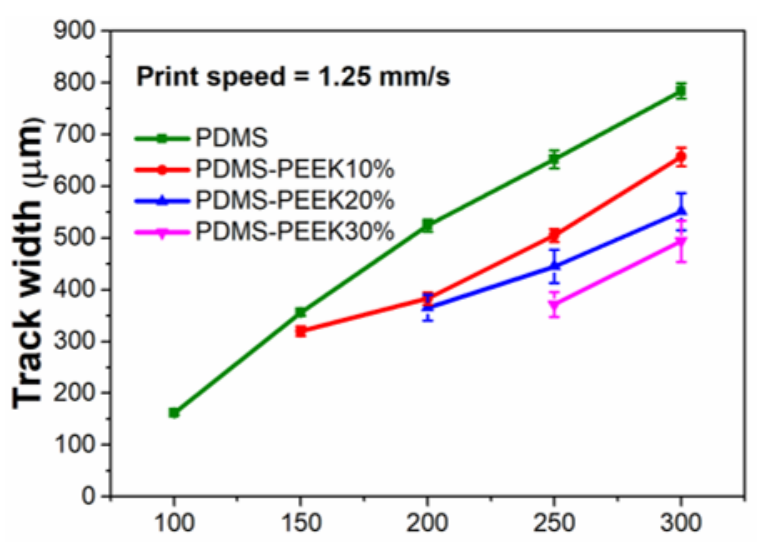

(a) Displacement $(\mathrm{P} / \mu \mathrm{l})$

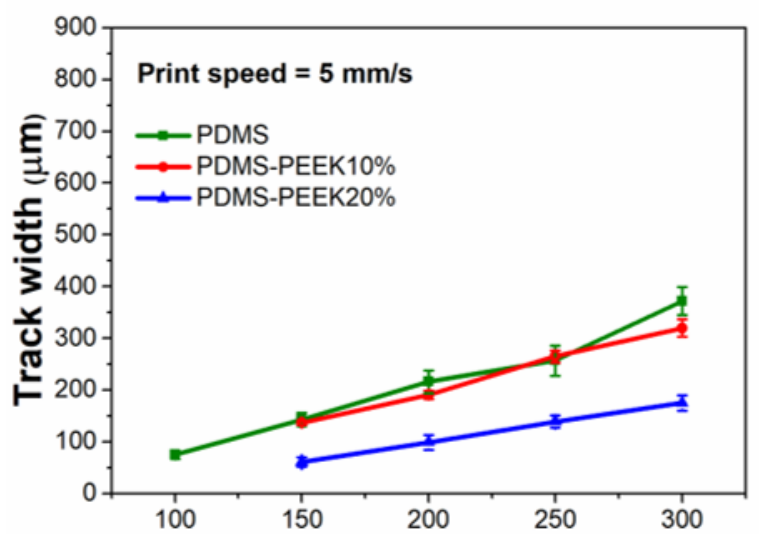

(c) Displacement $(\mathrm{P} / \mu \mathrm{l})$

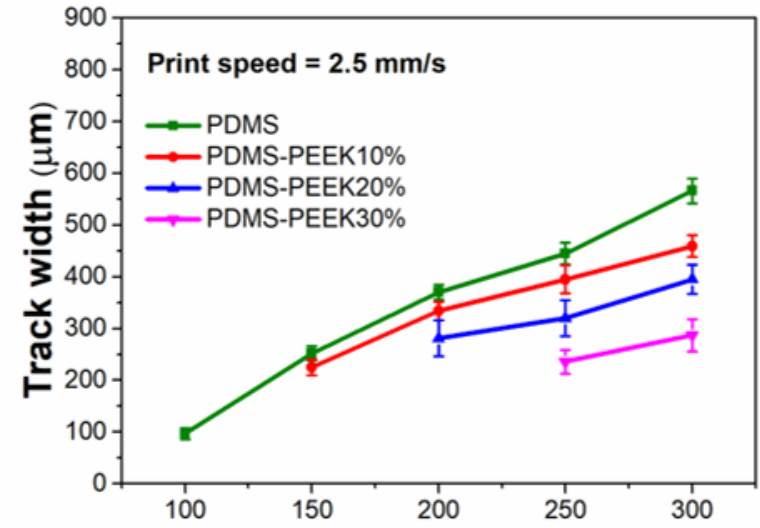

(b) Displacement $(\mathrm{P} / \mu \mathrm{l})$

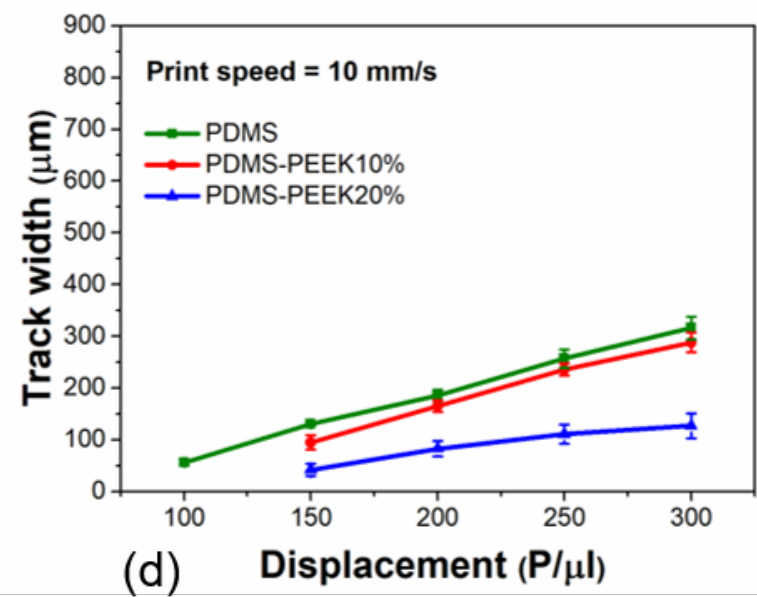

Fig. 5. Effect of positive displacement on track width for PDMS and PDMS-composites at (a) $1.25 \mathrm{~mm} / \mathrm{s}$, (b) 2.5 $\mathrm{mm} / \mathrm{s}$, (c) $5 \mathrm{~mm} / \mathrm{s}$, and (d) $10 \mathrm{~mm} / \mathrm{s}$. $\mathrm{N}=5$ tracks per combined variable (material composition, print speed and positive displacement), with 5 individual regions analysed per sample.

4 From a manufacturing perspective, there is a significant drive to produce components both efficiently and with required quality. Hence, data attained from the printability study were used as an initial guide to identify printing profiles. Initially, composite materials were processed at their highest printable speed and lowest levels of positive displacement in order to maximise production and prevent component distortion (through over extrusion). It was determined that speeds exceeding $5 \mathrm{~mm} / \mathrm{s}$ coupled with positive displacements of $100 \mathrm{P} / \mu \mathrm{l}$ were unable to accurately replicate the first print layer for mechanical test specimens due to high levels of distortion. For both PDMS-PEEK10\% and PDMS-PEEK20\%, print speeds had to be dropped 
1 to $2.5 \mathrm{~mm} / \mathrm{s}$, because of adherence issues that led to warp and build irregularities. In addition,

2 positive displacement values rose to $150 \mathrm{P} / \mu \mathrm{l}$ (PDMS-PEEK10\%) and $200 \mathrm{P} / \mu \mathrm{l}$ (PDMS-

3 PEEK20\%), respectively, as values below these levels caused flow inconsistencies. This trend

4 was further heightened with the inclusion of 30 wt.\% PEEK, whereby positive displacement

5 rose to $300 \mathrm{P} / \mu \mathrm{l}$ and print speed declined to $1.25 \mathrm{~mm} / \mathrm{s}$ for the manufacture of multi-layer test

6 specimens.

7 To demonstrate PDMS-PEEK printability, geometries varying in complexity and structural

8 density were explored. This included the fabrication of porous tissue scaffolds with variable

9 surface roughness (through ranging PEEK content) (Fig. 6), a dense octopus with overhangs

10 printed from viscous PDMS-PEEK30\% (Fig. 7 a) and hollow vessels for arterial replacement,

11 with those containing higher PEEK content presenting higher shape fidelity (Fig. 7 b). Finally,

12 a spatially graded honeycomb structure was produced with varying levels of mechanical

13 performance through its structure (Fig. 7 c). Further topological (Fig. S1 and Table S1) and

14 cross-sectional studies (Fig. S2) of PDMS-PEEK spatially graded specimens are presented in

15 supporting information. 


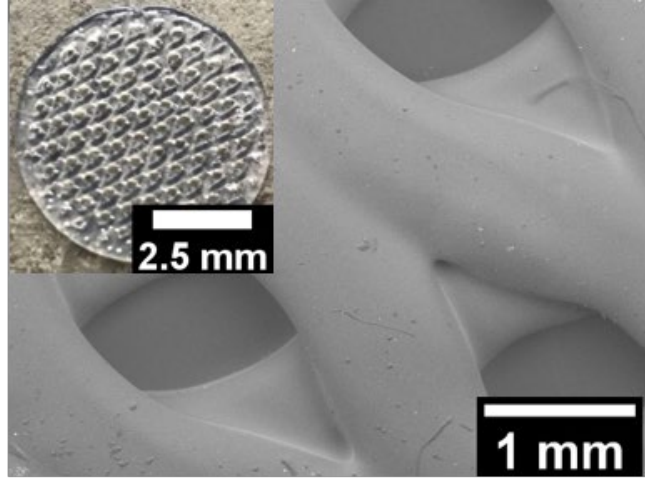

(a)

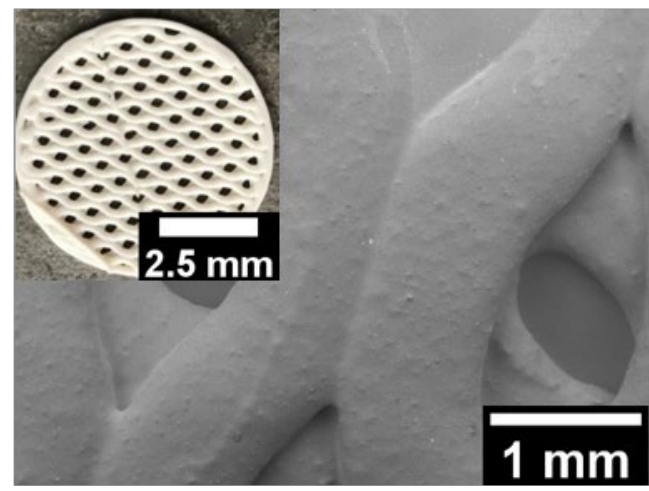

(c)

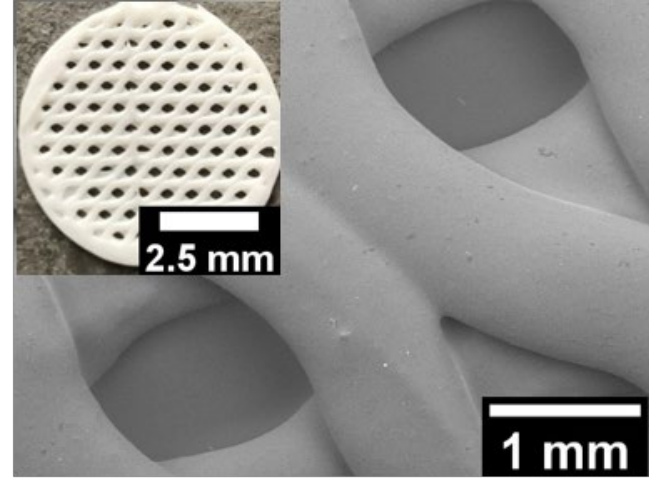

(b)

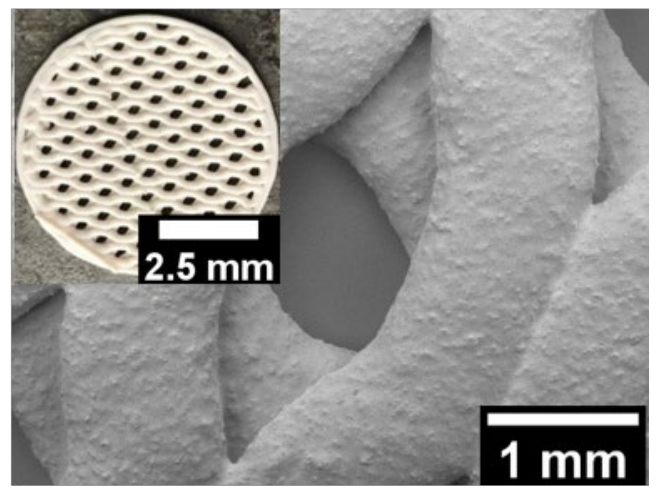

(d)

Fig. 6. SEM images and macroscopic photos (insets); 3D printed scaffolds fabricated from (a) PDMS, (b) PDMSPEEK $10 \%$, (c) PDMS-PEEK20\% and (d) PDMS-PEEK30\%.

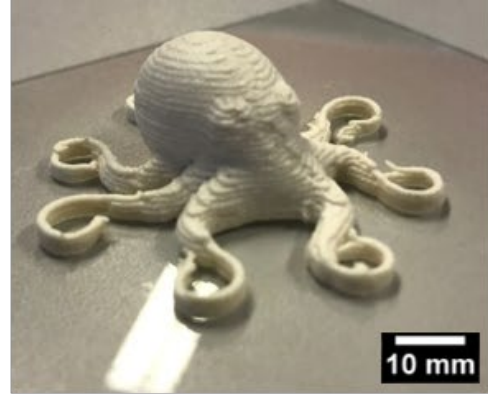

(a)

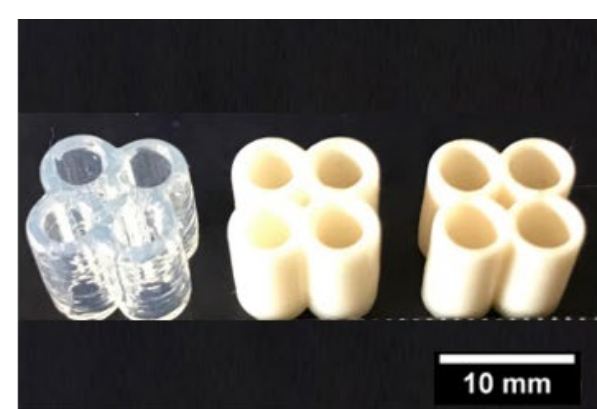

(b)

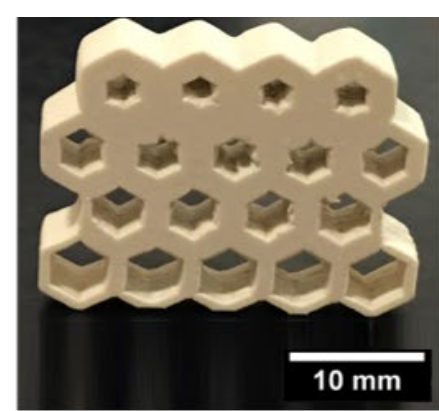

(c)

Fig. 7. (a) Printed octopus shape - PDMS-PEEK30\%; (b) hollow arterial vessel structures: PDMS (left), PDMS-

4 To form a solid PDMS component, hydrosilation reactions must occur between terminal vinyl

5 groups of siloxanes and methylhydrogen siloxane units [49]. The addition of a platinum 
1 catalyst promotes such chemical reactions; however, full cure can be readily accelerated by

2 increasing exposure temperature [50]. Previously, cast PDMS-PEEK samples were successfully cured at $70^{\circ} \mathrm{C}$ for $1 \mathrm{~h}$ [21]. It was therefore determined to apply the same testing conditions to printed specimens as a baseline. Another series of printed components was held at $150^{\circ} \mathrm{C}$ for 5 mins, in line with manufacturer recommendation for PDMS [51]. When assessing specimens held at $70^{\circ} \mathrm{C}$ for $1 \mathrm{~h}$, samples remained uncured. This was also true for PDMS and PDMS-PEEK specimens held at $150^{\circ} \mathrm{C}$ for 5 mins respectively.

After $6 \mathrm{~h}$ at $70^{\circ} \mathrm{C}$, the bulk of the printed specimens remained uncured; however, their exterior surfaces were shiny and rubberised to the touch. Full cure of both specimens was successfully achieved after $24 \mathrm{~h}$ at $70^{\circ} \mathrm{C}$ and $1 \mathrm{~h}$ at $150^{\circ} \mathrm{C}$, a noticeable increase vs. previously cast counterparts (credited to variation in manufacturer formulation). Observations demonstrated distinct variation between the groups of specimens. Those held at lower temperatures appeared to retain their printed geometry. In contrast, specimens held at $150^{\circ} \mathrm{C}$ were distorted, exhibiting a dome-like appearance, which became more prominent with rising PEEK content (Fig. 8). The diameter and height of printed PDMS-PEEK composites held at $70^{\circ} \mathrm{C}(24 \mathrm{~h})$ and $150^{\circ} \mathrm{C}(1 \mathrm{~h})$ are presented in Table S2 (see supporting information). As temperatures increased from $70^{\circ} \mathrm{C}$ to $150^{\circ} \mathrm{C},+9.47 \%$ (PDMS), $+8.14 \%$ (PDMS-PEEK $10 \%$ ), $+6.40 \%$ (PDMS-PEEK20\%) increases and a -7.07\% (PDMS-PEEK30\%) decrease were recorded. When assessing the height, the specimens printed at $150^{\circ} \mathrm{C}$ showed rises of $+19.1 \%$ (PDMS), $+37.3 \%$ (PDMS-PEEK10\%), +45.1\% (PDMS-PEEK20\%) and +24.6\% (PDMS-PEEK30\%) respective to counterparts held at $70^{\circ} \mathrm{C}$. Regions of porosity seen post-cure were attributed to the movement of gases (air entrapped during composite fabrication and by-products of hydrosilation reactions) throughout the composites during the curing process $[52,53]$. Upon cure, various physical phenomena (surface tension, viscous forces and phase change) act on internal gases, consequently causing their expansion and rise [54]. At lower temperatures, gases had sufficiently more time to escape the composite structure prior to cure, leading to maintenance of the structural geometry. However, when exposed to elevated temperatures, 
1 the exterior of the matrix cured before the bulk, preventing gas escaping and leading to

2 deformation. Furthermore, the introduction of solid fractions is known to hinder bubble

3 coalescence and migration, which resulted in the formation of porous structures and

4 reductions in composite density [55]. Reductions in mechanical performance (in terms of

5 stiffness and ultimate tensile strength) with rising temperatures $\left(100-300^{\circ} \mathrm{C}\right)$ and curing times

6 (0.5-3.5 h) have been reported for PDMS, with causation attributed to thermal degradation

7 through bond cleavage [56-58]. It was therefore conjectured that the induced levels of porosity

8 with higher curing temperatures could compromise the range of attainable performance in

9 mechanical tests. Hence, the specimens were cured at $70^{\circ} \mathrm{C}$ for $24 \mathrm{~h}$ in subsequent studies.

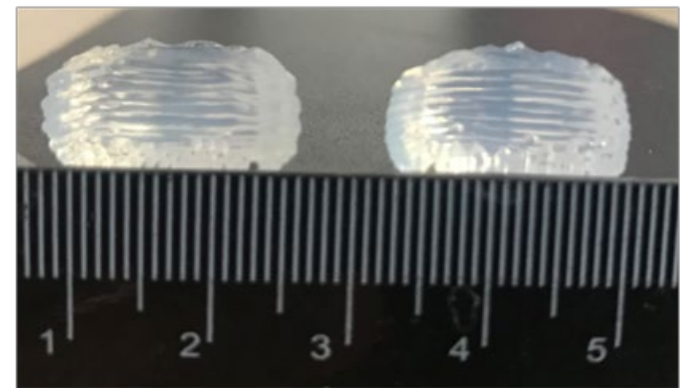

(a)

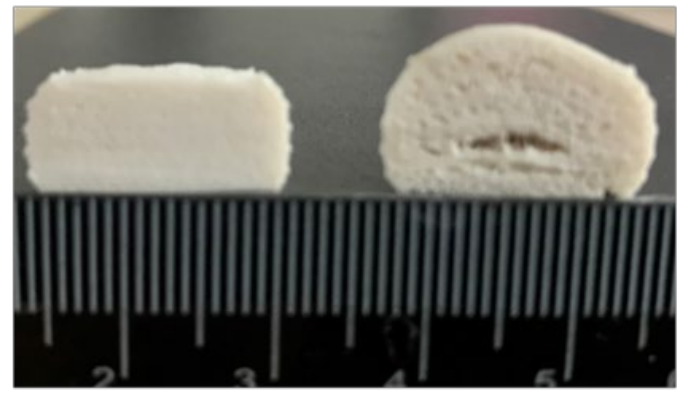

(c)

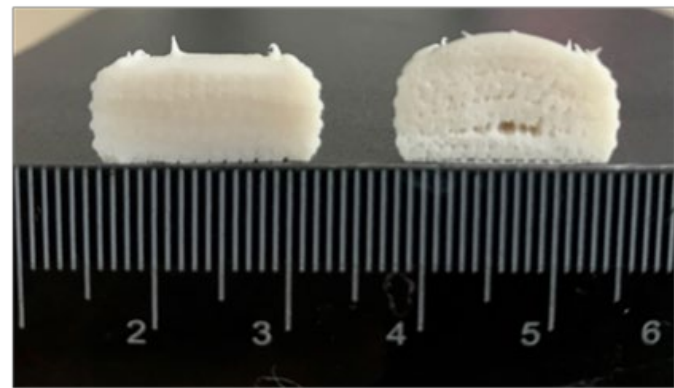

(b)

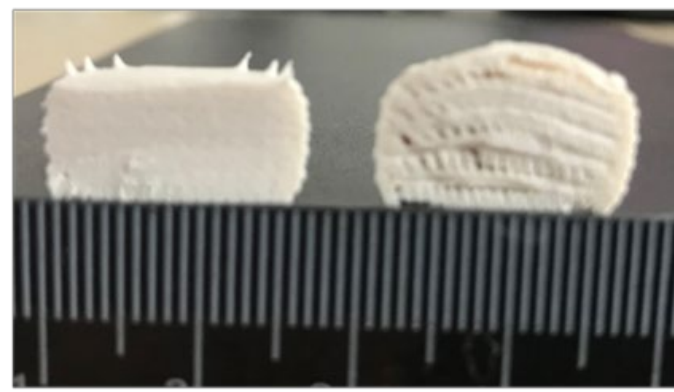

(d)

Fig. 8. 3D printed specimens; (a) PDMS, (b) PDMS-PEEK10\%, (c) PDMS-PEEK20\% and (d) PDMS-PEEK30\% cured at $70^{\circ} \mathrm{C}$ (left of photo) and $150^{\circ} \mathrm{C}$ (right of photo) [ruler scale in $\mathrm{cm}$ ].

\subsection{Mechanical Performance}

\subsubsection{Solid samples}

\section{Shore A hardness}

Assessment of Shore A hardness has become a routine method to characterise a medical material's resistance to deformation, e.g. for facial prosthetics [59]. It is known that the 
1 mechanical behaviour of the tissues they aim to replace changes with age; hence, PDMS-

2 PEEK specimens were tested to attain performance levels and identify suitable application

3 [60]. As consequence of PEEK particle reinforcement, a range of Shore A hardness values

4

5

6

7

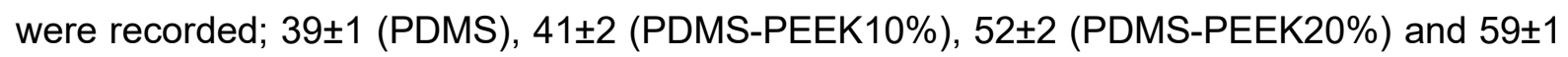
(PDMS-PEEK30\%) (Fig. 9 a). Statistically significant $(p<0.05)$ increases in performance were found for both the intrinsic hardness of PEEK (Shore D 95) relative to PDMS and its restriction on siloxane chain movement upon the application of load, increasing resistance to deformation $[61,62]$. Compared to LSR inks adopting chain extenders (CE) and photoinitiatorbased chemistry, PDMS-PEEK30\% demonstrated similar values to those containing $60-80$ mol\% CE (63-56) while PDMS-PEEK20\% reported values close to 80-90 mol\% CE (56-45) [16]. Studies performed by Periyasamy et al. anatomically compartmentalised the human foot into eight separate regions with hardness values between 20-43 [63]. Thus, the use of appropriate PEEK fractional volumes could be used in the manufacture of prostheses or surgical phantoms with graded material hardness.

\section{Tension and compression}

Obtained stress-strain curves revealed small linear ranges ( 0.2 strain), before the onset of plastic deformation and failure in tension (Fig. 9 b) with J-shape curves observed in compression (Fig. 9 c), similar to other PDMS-based materials $[13,64]$. The tensile modulus was $0.60 \pm 0.1 \mathrm{MPa}$ for PDMS, increasing by $3 \%$ (PDMS-PEEK10\%), 150\% (PDMSPEEK20\%) and 113\% (PDMS-PEEK30\%) (Fig. 9 d, left). Similarly, the compressive modulus of PDMS rose with the addition of PEEK, gaining $+19 \%+102 \%$ and $+249 \%$ for PDMSPEEK10\%, PDMS-PEEK20\%, and PDMS-PEEK30\% (Fig. 9 d, right), respectively. Statistically significant rises $(p<0.05)$ in tensile and compressive moduli were found as PEEK particle fractions increased to $20 \mathrm{wt} . \%$ and beyond. The UTS values significantly reduced $(p<0.05)$ by 53\% (PDMS-PEEK10\%), 11\% (PDMS-PEEK20\%) and 8\% (PDMS-PEEK30\%) with increasing PEEK content (Fig. 9 e). Unlike in tension, the peak stress rose in compressive specimens, growing by $10 \%$ for PDMS-PEEK $10 \%$, 91\% for PDMS-PEEK $20 \%$ and $94 \%$ for 
1 PDMS-PEEK30\% over the PDMS control, with statistical rises observed as fractional content

2 increased from 20 wt.\% upwards (Fig. 9 f). Significant declines in elongation at break observed

3 upon rising PEEK content, recording $-35 \%$ for PDMS-PEEK10\%, -36\% for PDMS-PEEK20\%

4 and $-67 \%$ for PDMS-PEEK30\% relative to PDMS (Fig. $9 \mathrm{~g}$ ). This was also the case for

5 elongation at break in compression: -4\% (for 10 wt.\% PEEK), -5\% (for 20 wt.\% PEEK) and -

$68 \%$ (for 30 wt.\% PEEK) decreases with respect to PDMS (Fig. 9 h). 


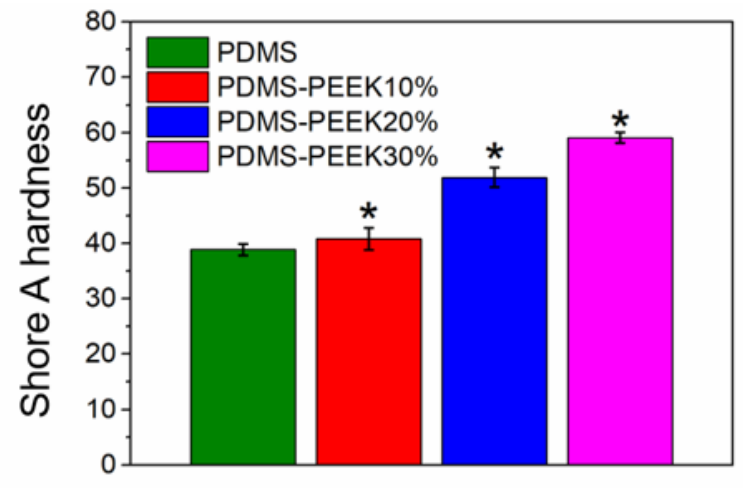

(a)

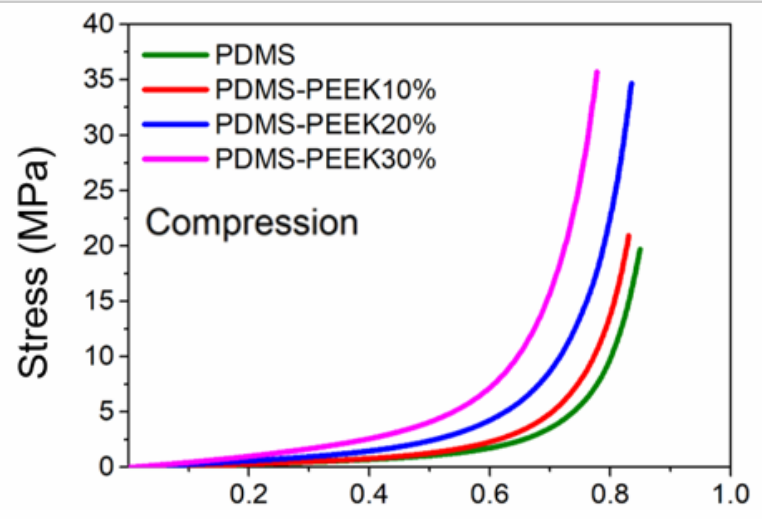

(c)

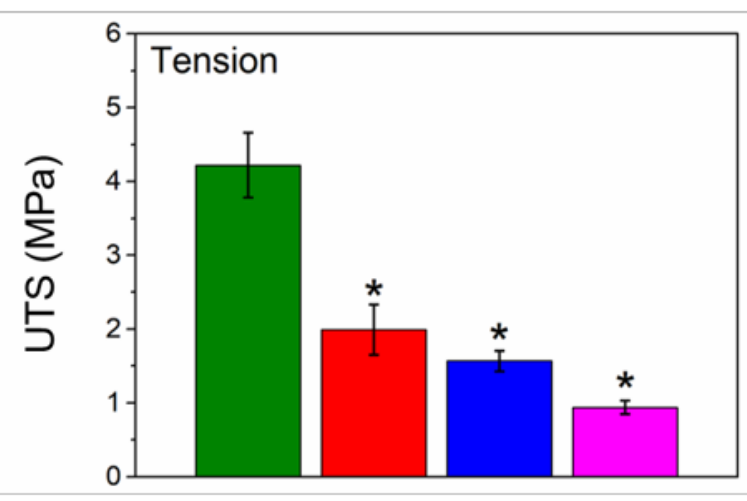

(e)

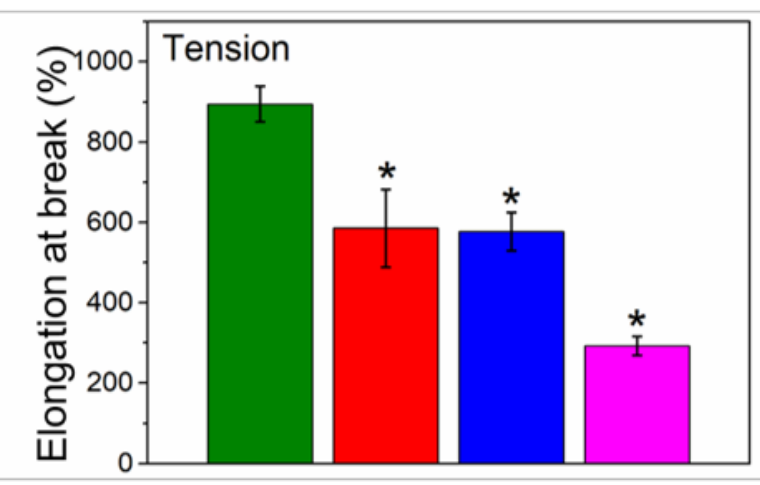

(g)

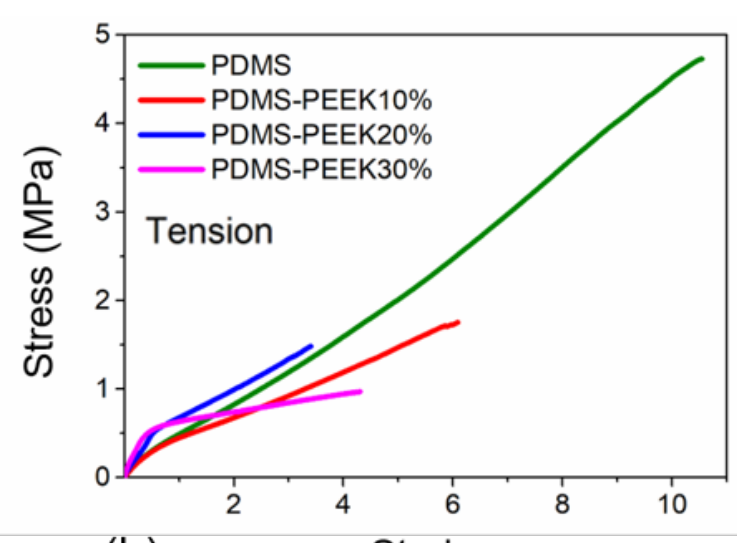

(b)

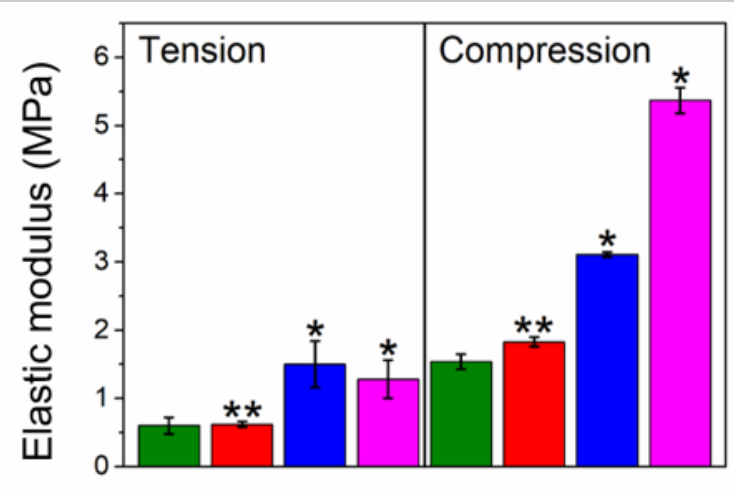

(d)

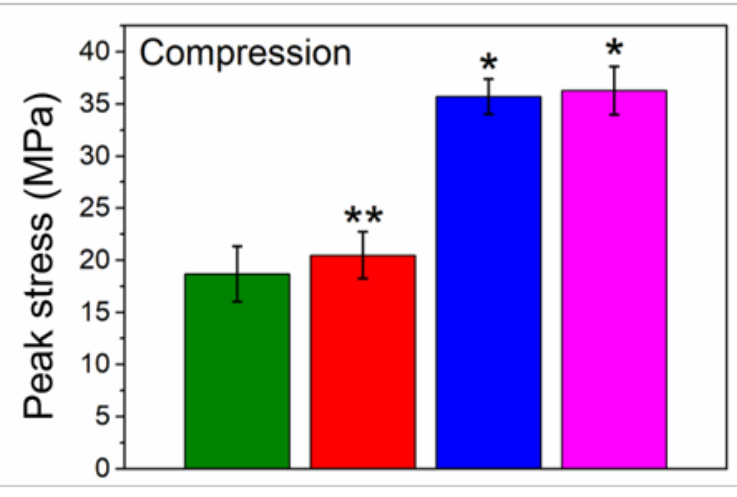

(f)

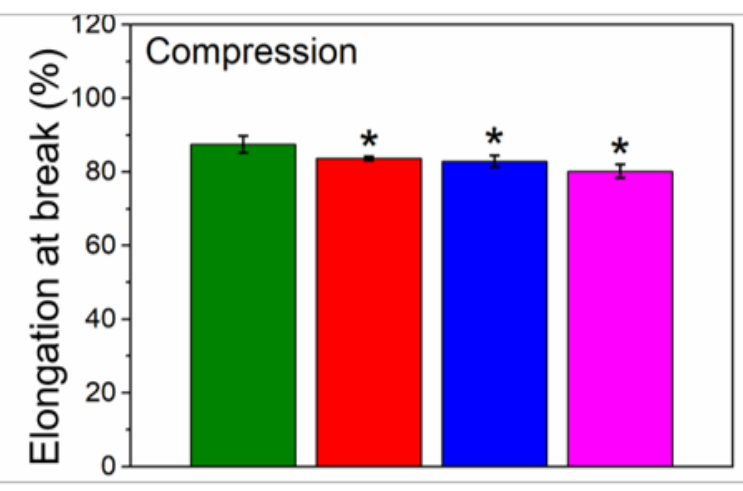

(h) 
Fig. 9. Mechanical performance of bulk specimens; (a) Shore A hardness, (b) stress-strain graph [non-averaged curves] in tension and (c) compression, (d) elastic modulus in tension (left) and compression (right), (e) ultimate tensile strength, (f) peak stress and elongation at break in (g) tension and (h) compression for and PDMS and PDMS-PEEK composites. *Statistical significance $(p<0.05)$ and ${ }^{* *}$ no-statistical significance $(p>0.05)$ observed compared to PDMS control.

2 Comparing PDMS-PEEK composites with printed PDMS/silicones in the literature, the tensile 3 modulus of the PDMS control was consistent with existing reports $[8,10,16]$. Compared to LSR 4 inks with ranging chain extender (CE) ratios, PDMS-PEEK20\% showed $37 \%(0$ mol\%), 55\% 5 (20 mol\%), 71\% (40 mol\%), 73\% (60 mol\%), 85\% (80 mol\%) and $91 \%$ (90 mol\%) increases 6 in elastic moduli [16]. Rises in elastic modulus can be related to the high stiffness of PEEK 7 particles, which had the capacity to dissipate greater loading across the soft-polymer matrix 8 i.e. better at resisting deformation due to restrictive nature on siloxane chains [65-67]. 9 Declines of both UTS and elongation at break with increasing PEEK loading were caused by growing particles agglomerates in the system, encouraging dewetting, and leading to rupture (Fig. 10) [68]. Post-testing, it was determined that voids also existed within the PDMSPEEK20\% and PDMS-PEEK30\% specimens (Figs. 10 c \& d). This was attributed to both reduction in elastomer content (rise of solid particle loading) and rise in pre-cure viscosity, which prevented complete bonding/fusing between adjacent layers [23]. Subsequently, this led to inhomogeneous deformation leading to the early onset of failure, which was also reported in [23]. Unlike both PDMS-PEEK20\% and PDMS-PEEK30\%, voids from the printing process were not present in the other composites. This was thanks to the fluid nature of PDMS, encouraging the formation of strong bonds between adjacent and subsequent layers (these were indistinguishable along the $x-y, y-x$ and $x-z$ direction) after extrusion. 


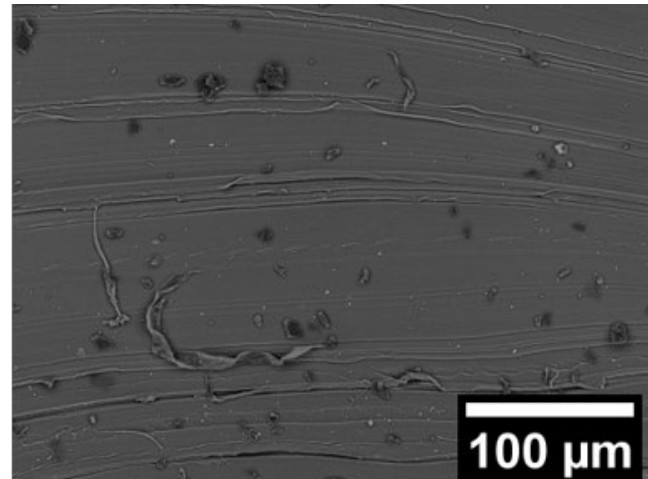

(a)

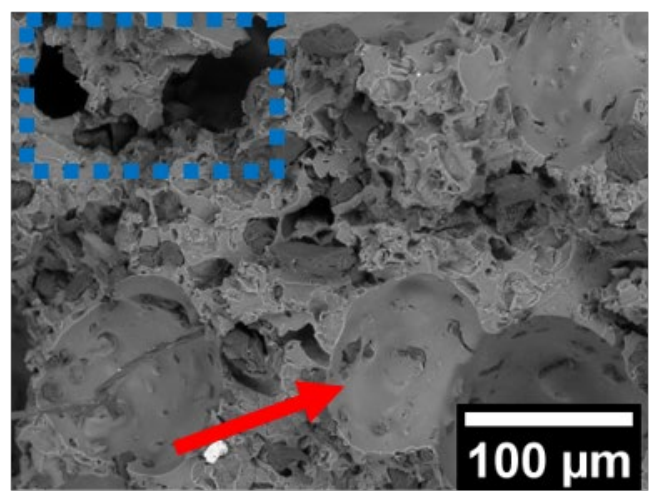

(c)

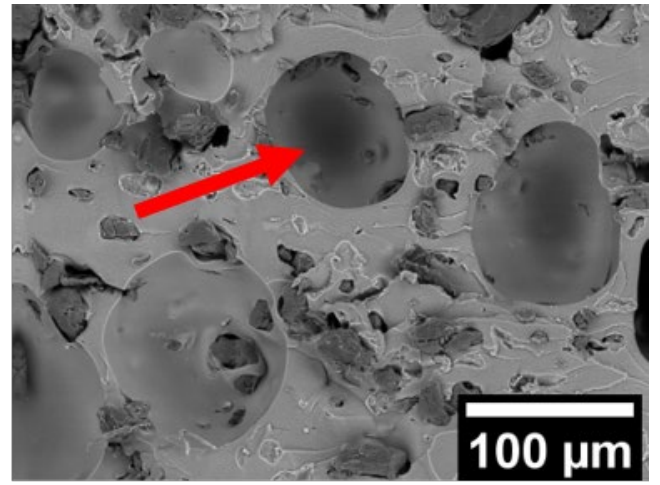

(b)

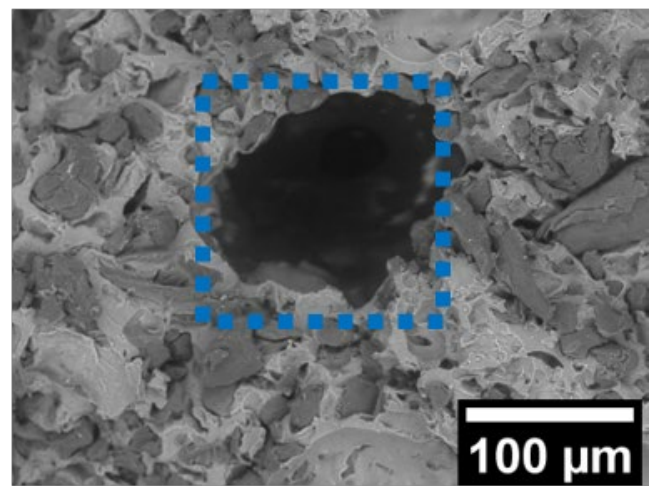

(d)

Fig. 10. SEM images of tensile specimen's fracture surfaces post-testing; (a) PDMS, (b) PDMS-PEEk10\%, (c) PDMS-PEEK20\% and (d) PDMS-PEEK30\%. Air entrapment (red arrow) and void (blue boxes) are highlighted.

Like in tension, specimens with higher volumes of PEEK resisted deformation better in compression. Upon the onset of plastic deformation, small tears formed along the side-walls of the PDMS-PEEK composites at the start/end point of the outer content (Figs. 11 a, c \& d). As deformation increased, the dimensions of the fracture site increased as the chemical bonds binding the matrix were cleaved. Consequently, the exterior wall of the printed specimens began to detach from the bulk infill, in a 'spiral-like' fashion for PDMS, PDMS-PEEK20\% and PDMS-PEEK30\%. This phenomenon was linked to a combination of factors including the gcode tool path, flow behaviour of the composites (capillary, viscous and inertial forces) and physio-chemical interactions between the blended polymers [69,70]. Rheological analysis confirmed a rise in viscosity with increasing PEEK fractions, with composites containing 20 wt.\% and 30 wt.\% PEEK demonstrating a reduction in flowability and 'stickiness'. This caused structural weaknesses between print layers that promoted detachment under loading [70]. In 
1 contrast, PDMS and PDMS-PEEK10\% could flow and deviate from its deposition site post-

2 print (Figs. $11 \mathrm{a} \& \mathrm{~b}$ ), enabling the material to fill voids or gaps within the build [70]. Hence,

3 thanks to greater uniformity of its structure, PDMS-PEEK10\% did not demonstrate complete

4 burst (Fig. 11 b). The rupture in PDMS was due to its weaker mechanical performance.

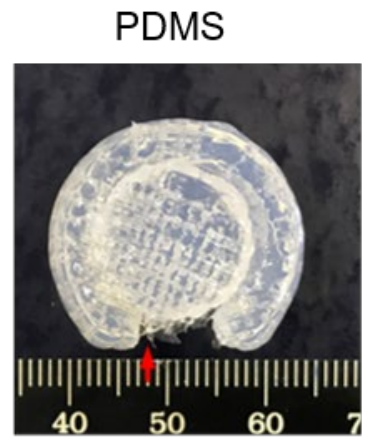

(a)

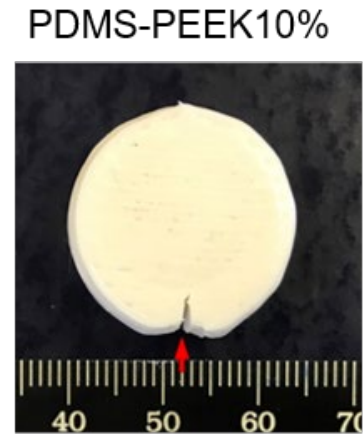

(b)

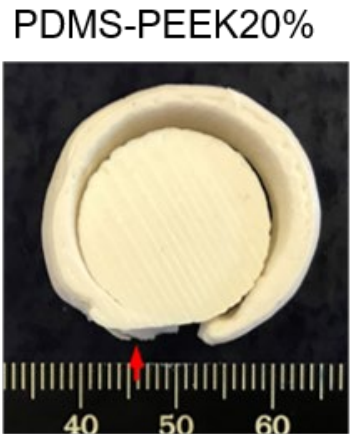

(c)

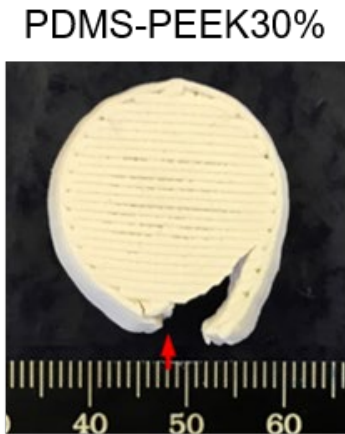

(d)

Fig. 11. Bulk (100\% infill) PDMS-PEEK composites after compression testing at $0.001 \mathrm{~s}^{-1}$. Red arrows indicate exterior rupture point leading to specimen failure [ruler scale in $\mathrm{mm}$ ].

\subsubsection{Spatially graded samples}

Manipulating the infill density of printed material through its volume can alter its mechanical performance; this process is known as functional grading [71-73]. Such structures are commonly found in nature, including the human body, in the form of soft-to-hard tissue gradients. However, prior to the emergence of AM, such geometrically complex builds were challenging to replicate with conventional manufacturing processes, with failure often occurring between contrasting material interfaces.

In this study, the variable densification of PDMS-PEEK composites was implemented with spatial grading at $20 \%, 40 \%$ and $60 \%$ infill (specimens with $80 \%$ infill density were not reported due to material overflow). As consequence of grading PDMS (with up to $30 \mathrm{wt} \%$ PEEK) from $20-60 \%$ infill, a range of stiffnesses (0.70-2.34 MPa) was successfully attained; the main results are shown in (Fig. 12 a). However, such trends were not significantly $(p<0.05)$ different from those printed at $100 \%$ infill. This was due to the consolidation of PDMS components in compression, with internal strut elements buckling inwards as result of non-uniformity across the surface of the specimen. 
1 Such phenomenon was reported for components produced with ME-based printing, which can

2 have large $( \pm 50 \%)$ mechanical variability between samples and within the build $[74,75]$. Unlike

3 the control, PDMS-PEEK10\% exhibited statistically significant reductions $(p<0.05)$ in stiffness

4 as infill density was decreased to $20 \%$ and $40 \%$. This behaviour was related to a reduction in

5 material volume, whereby the removal of matter reduced the stiffness of the build, causing the

6 earlier onset of plastic deformation [76,77]. As infill density was increased, rises in peak stress

7 values were attained across all composite sets; however, the inclusion of PEEK content saw

8 such values decline (Fig. 12 b). At 20\% infill, PDMS-PEEK20\% and PDMS-PEEK30\%

9 recorded significant declines $(p<0.05)$ in peak stress compared to the PDMS control. This

10 behaviour was also recorded when infill density was further increased to $60 \%$. For PDMS,

11 PDMS-PEEK10\% and PDMS-PEEK20\% no significant changes in elongation at break were

12 found irrespective or varying infill density (Fig. 12 c). This was true of PDMS-PEEK30\% at

$1340 \%$ and $60 \%$ infill; however $20 \%$ specimens showed significantly higher levels $(p<0.05)$, as

14 a result of particle agglomeration and increase in unbound rubber content, allowing the

15 structure to deform plastically at a greater rate $[78,79]$.

16 Through the adoption of ME, a greater range of mechanical properties was attained for PDMS-

17 PEEK composites in compression: for instance, elastic moduli were recorded as 0.70-5.37

$18 \mathrm{MPa}(\mathrm{ME})$ vs. 1.46-4.70 MPa (cast) [21]. Furthermore, the elastic moduli for cast PDMS

19 specimens could be matched - or even enhanced - in the test specimens with variable infill:

20 this is the case for ME PDMS at $60 \%$ infill, for PDMS-PEEK $10 \%$ and PDMS-PEEK $20 \%$ at $40 \%$

21 infill and for PDMS-PEEK30\% at $20 \%$ infill. Consequently, reducing final component weight

22 and material use, which is advantageous for many end-use applications. 


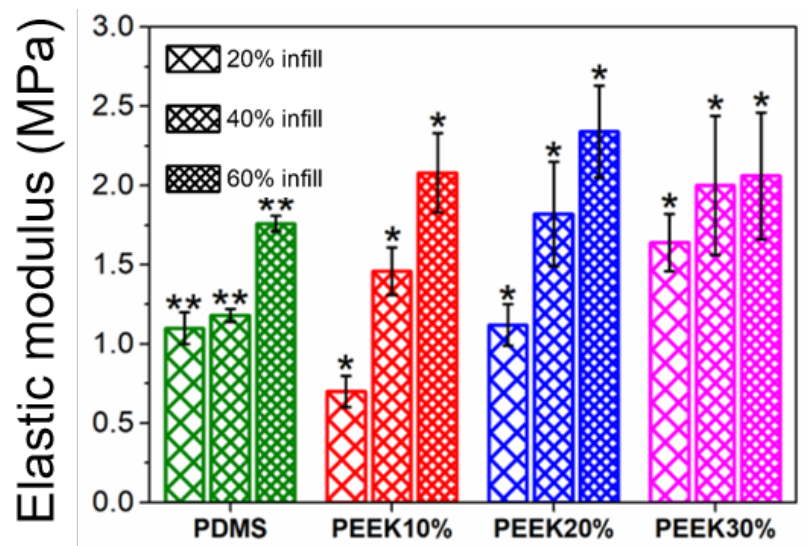

(a)

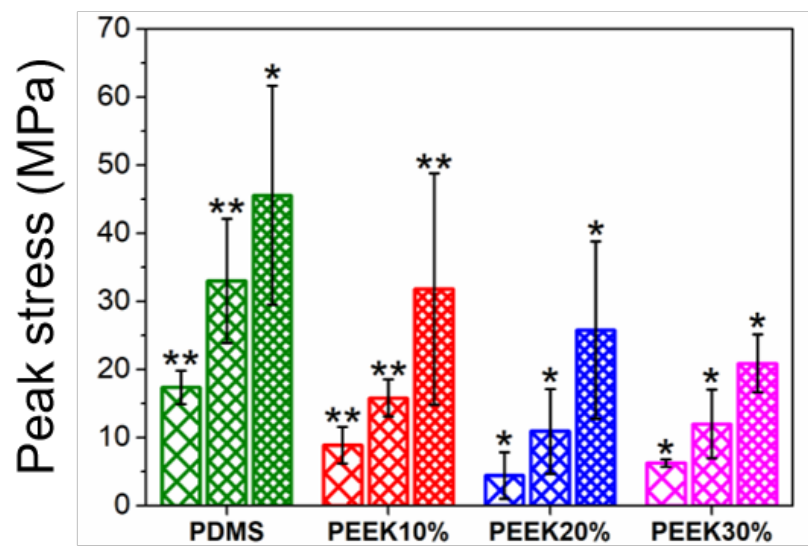

(b)

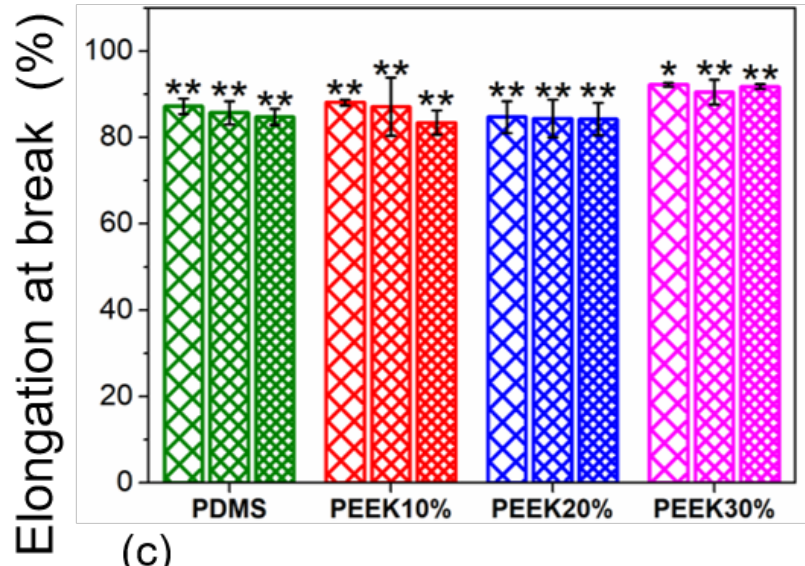

Fig. 12. Mechanical performance of spatially graded [20-60\%] PDMS and PDMS-PEEK composites; (a) elastic modulus, (b) peak stress and (c) elongation at break. *Statistical significance $(p<0.05)$ and **no-statistical significance $(p>0.05)$ compared to their $100 \%$ infill specimens.

2 Post-test observations can provide valuable insights into the deformation mechanics of bulk

3 materials and structures and supplement attained experimental data. At the lowest infill (20\%),

4 PDMS demonstrated failure in the form of side-wall rupture, which continued to propagate

5 throughout the lattice strut formations in a burst-like fashion (Fig.13 a). PDMS-PEEK10\% 
1 specimens had a similar failure mechanism, with small splits through its side-wall and strut

2 failure permeating from the outside in (Fig. 13 b). Notably, strut damage was not as severe as

3 that of PDMS. Splits at the join and general circumference were observed in PDMS-PEEK20\%

4 samples (Fig. 13 c). Strut damage was located towards the top of the specimens only, with

5 the remaining structure appearing more intact than PDMS and PDMS-PEEK10\%. Like the

6 other composites, PDMS-PEEK30\% displayed side-wall failure across its build (Fig. $14 \mathrm{~d}$ ).

7 Lattices located within the build demonstrated brittle-like rupture, but like PDMS-PEEK20\%,

8 most of its internal structure remained intact.

9 At $40 \%$-infill, PDMS exhibited similar deformation behaviour to their $20 \%$-infill counterparts, 10 whereby fracture occurred toward the join of the specimen, propagating into nearby strut 11 formations and causing rupture (Fig. 13 e). Incremental loads of 10 wt.\% PEEK reduced the 12 number of side wall splits across the polymer matrix; however, the route of failure persisted 13 towards the join of the specimen (Fig. 13 f). As consequence of rising infill density, reductions in strut damage were observed. PDMS-PEEK20\% and PDMS-PEEK30\% exhibited far greater numbers of brittle cracks through the side (Figs. $13 \mathrm{~g} \& \mathrm{~h}$ ).

As infill density increased to $60 \%$, PDMS demonstrated crack propagation at the join of the specimen (Fig. 13 i). Still, strut damage across the samples reduced. Single fracture sites were seen across the PDMS-PEEK10\% specimens; however, unlike previous composites structures, all lattice structures remained whole (Fig. $13 \mathrm{j}$ ). This behaviour was repeated in PDMS-PEEK20\% and PDMS-PEEK30\% specimens (Figs. 13 k \& I). In compression, specimens with higher infill density and PEEK content showed enhanced levels of stiffness. Generally, it was determined that the structural integrity of PDMS rose with incrementing PEEK particle content and infill density. 


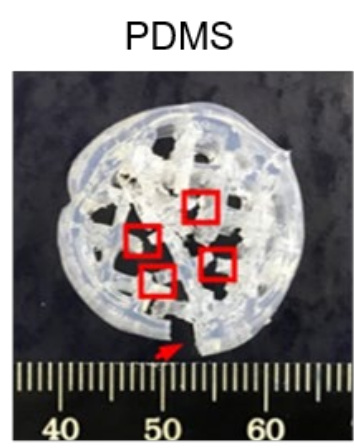

(a)

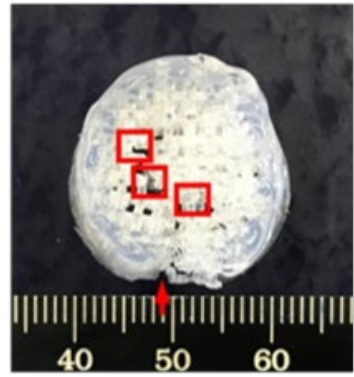

(e)

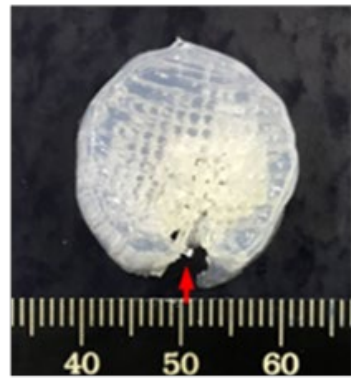

(i)

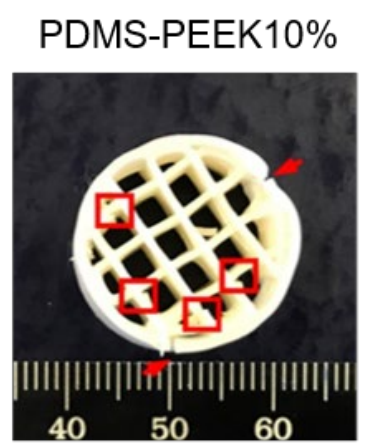

(b)

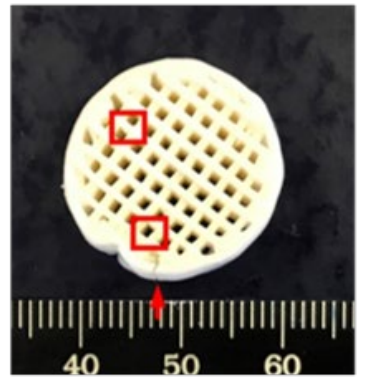

(f)

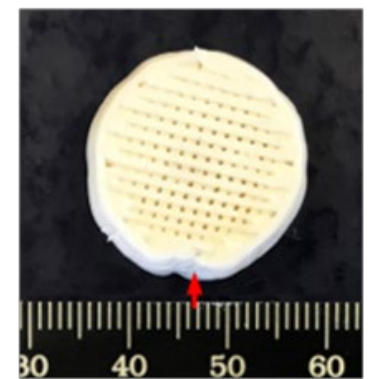

(j)

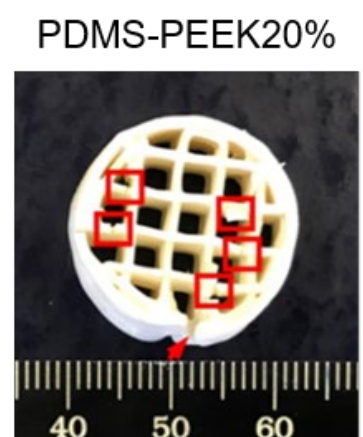

(c)

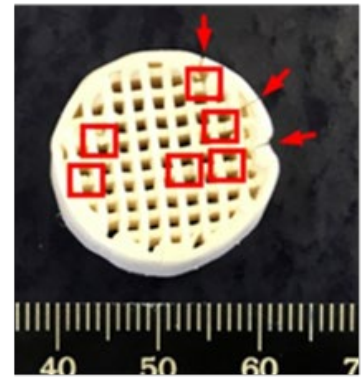

(g)

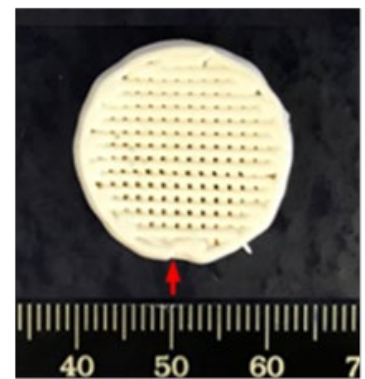

(k)
PDMS-PEEK $30 \%$

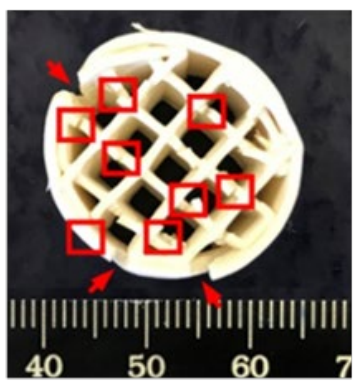

(d)

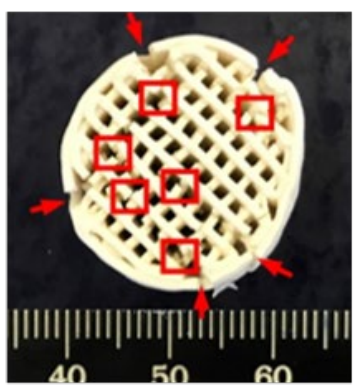

(h)

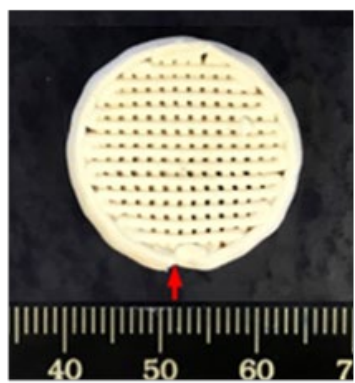

(I)

Fig. 13. Spatially graded PDMS-PEEK composites at 20\% infill (a-d), 40\% infill (e-h) and 60\% infill (i-l) postcompression testing at $0.001 \mathrm{~s}^{-1}$. Red arrows indicate exterior rupture points leading to specimen's failure [ruler

scale in $\mathrm{mm}$.

\section{Conclusions}

This work investigated the printability of biomedical PDMS-PEEK composites (up to $30 \mathrm{wt} . \%$

PEEK) produced with ME and assessed the effects of spatial grading on their mechanical

performance. Rheological characterization revealed that all composites were shear-thinning

(above $\left.0.7 \mathrm{~s}^{-1}\right)$, self-supporting at rest $\left(0.1 \mathrm{~s}^{-1}\right)$ and exhibited individual thixotropic recovery

rates (18.0-39.0 s). It was found that rising PEEK concentration increased matrix viscosity;

however, flowability was induced earlier at rising shear rate. All materials demonstrated

thixotropic rebuild and dominant storage moduli, with those containing 20 wt. $\%$ and beyond 
1 significantly increasing rebuild rates due to perikinetic motion. PDMS-PEEK tracks were

2 extruded at various speeds $(1.25-10.00 \mathrm{~mm} / \mathrm{s})$ and positive displacement $(100-300 \mathrm{pulses} / \mu \mathrm{l})$

3 to identify printability windows. As consequence of PEEK fractional loading, print speeds were

4 reduced, and positive displacement values were risen to accommodate rising viscosity; this

5 translated into bespoke printing conditions for each composite material. It was concluded that

6 higher temperatures increased the rate of cure; however, a trade-off in shape fidelity was

7 observed. In tension, significant rises in stiffness were recorded as PEEK fractional volumes

8 increased beyond 20 wt.\%, accompanied by a decline in both UTS and elongation values.

9 Similarly, 20 wt.\% and 30 wt.\% PEEK particle content increased stiffness levels in compression, caused by rises in siloxane chain restriction (internal friction). Declines in stiffness were linked with lower infill density, as there was less material to bear the applied loading. Statistically significant increases in Shore A hardness were observed with incrementing PEEK content. The deposition of PDMS-PEEK composites (with ranging PEEK content) within a single build could lead to the fabrication of highly tailored medical devices and implants with controllable mechanical gradients throughout, better mimicking the native tissues of the human body (previously unachievable with conventional casting methods).

17 Further optimisation coupled with reductions in nozzle size can be used to produce more intricate scaffold-like structures for commercial medical applications by material extrusion technologies.

\section{Acknowledgements}

21 This work was supported via the EPSRC Centre for Doctoral Training in Additive 22 Manufacturing (EP/L01534X/1) and the National Institute of Health Research (NIHR) Children 23 and Young People MedTech Co-operative (NIHR CYP MedTech). The views expressed are 24 those of the author(s) and not necessarily those of the NHS, the NIHR or of the Department 25 of Health. 
1 CRediT authorship contribution statement

2 James A. Smith: Conceptualization, Methodology, Validation, Formal analysis, Investigation,

3 Visualization, Writing - Original Draft. Simin Li: Conceptualization, Supervision, Funding

4 acquisition, Resources, Writing - review \& editing. Elisa Mele: Conceptualization,

5 Supervision, Funding acquisition, Resources, Writing - review \& editing. Athanasios Goulas:

6 Investigation, Resources, Writing - review \& editing. Daniel S. Engstrøm: Resources, Writing

7 - review \& editing. Vadim V. Silberschmidt: Conceptualization, Supervision, Funding

8 acquisition, Resources, Writing - review \& editing 


\section{6. References}

3 [1] F. Abbasi, H. Mirzadeh, A.A. Katbab, Modification of polysiloxane polymers for biomedical applications: A review, Polym. Int. 50 (2001) 1279-1287. doi:10.1002/pi.783.

[2] V. Ozbolat, M. Dey, B. Ayan, A. Povilianskas, M.C. Demirel, I.T. Ozbolat, 3D Printing of PDMS Improves Its Mechanical and Cell Adhesion Properties, ACS Biomater. Sci. Eng. (2018) acsbiomaterials.7b00646. doi:10.1021/acsbiomaterials.7b00646.

[3] E.J. Courtial, C. Perrinet, A. Colly, D. Mariot, J.M. Frances, R. Fulchiron, C. Marquette, Silicone rheological behaviour modification for 3D printing: Evaluation of yield stress impact on printed object properties, Addit. Manuf. (2019). doi:10.1016/j.addma.2019.04.006.

[4] M.. Owens, Elastomers: Siloxane, Second, Elsevier, Amsterdam, 2001. doi:https://doi.org/10.1016/B0-08-043152-6/00448-4.

[5] B.D. Ratner, A.S. Hoffman, Biomaterials Science: An introduction to materials in medicine, 2013. doi:10.1016/B978-0-08-087780-8.00025-5.

[6] M.S. Mannoor, Z. Jiang, T. James, Y.L. Kong, K.A. Malatesta, W.O. Soboyejo, N. Verma, D.H. Gracias, M.C. McAlpine, 3D printed bionic ears, Nano Lett. (2013). doi: $10.1021 / \mathrm{n} \mid 4007744$.

[7] E.B. Duoss, T.H. Weisgraber, K. Hearon, C. Zhu, W. Small IV, T.R. Metz, J.J. Vericella, H.D. Barth, J.D. Kuntz, R.S. Maxwell, C.M. Spadaccini, T.S. Wilson, Three-dimensional printing of elastomeric, cellular architectures with negative stiffness, Adv. Funct. Mater. (2014). doi:10.1002/adfm.201400451.

[8] T.J. Hinton, A. Hudson, K. Pusch, A. Lee, A.W. Feinberg, 3D Printing PDMS Elastomer in a Hydrophilic Support Bath via Freeform Reversible Embedding, ACS Biomater. Sci. 
2 [9] C.S. O’Bryan, T. Bhattacharjee, S. Hart, C.P. Kabb, K.D. Schulze, I. Chilakala, B.S 3

Eng. 2 (2016) 1781-1786. doi:10.1021/acsbiomaterials.6b00170.

Sumerlin, W.G. Sawyer, T.E. Angelini, Self-assembled micro-organogels for 3D printing silicone structures, Sci. Adv. (2017). doi:10.1126/sciadv.1602800.

[10] N. Bhattacharjee, C. Parra-Cabrera, Y.T. Kim, A.P. Kuo, A. Folch, DesktopStereolithography 3D-Printing of a Poly(dimethylsiloxane)-Based Material with Sylgard184 Properties, Adv. Mater. (2018). doi:10.1002/adma.201800001.

[11] J. Holländer, R. Hakala, J. Suominen, N. Moritz, J. Yliruusi, N. Sandler, 3D printed UV light cured polydimethylsiloxane devices for drug delivery, Int. J. Pharm. (2018). doi:10.1016/j.jpharm.2017.11.016.

[12] F. Liravi, M. Vlasea, Powder bed binder jetting additive manufacturing of silicone structures, Addit. Manuf. (2018). doi:10.1016/j.addma.2018.02.017.

[13] Q. Chen, J. Zhao, J. Ren, L. Rong, P.-F. Cao, A.R. C, 3D Printed Multifunctional, Hyperelastic Silicone Rubber Foam, Adv. Funct. Mater. (2019) 1-9. doi:10.1002/adfm.201900469.

[14] F. Liravi, E. Toyserkani, A hybrid additive manufacturing method for the fabrication of silicone bio-structures: 3D printing optimization and surface characterization, Mater. Des. (2018). doi:10.1016/J.MATDES.2017.10.051.

[15] X. Wang, M. Jiang, Z. Zhou, J. Gou, D. Hui, 3D printing of polymer matrix composites: A review and prospective, Compos. Part B Eng. (2017). doi:10.1016/j.compositesb.2016.11.034.

[16] S. Zheng, M. Zlatin, P.R. Selvaganapathy, M.A. Brook, Multiple modulus silicone elastomers using 3D extrusion printing of low viscosity inks, Addit. Manuf. (2018). doi:10.1016/j.addma.2018.09.011.

[17] B. Baroli, Photopolymerization of biomaterials: Issues and potentialities in drug delivery, 
tissue engineering, and cell encapsulation applications, J. Chem. Technol. Biotechnol. (2006). doi:10.1002/jctb.1468.

[18] K.L. Van Landuyt, S. Krifka, K.A. Hiller, C. Bolay, C. Waha, B. Van Meerbeek, G. Schmalz, H. Schweikl, Evaluation of cell responses toward adhesives with different photoinitiating systems, Dent. Mater. (2015). doi:10.1016/j.dental.2015.04.016.

[19] A. Oesterreicher, M. Roth, D. Hennen, F.H. Mostegel, M. Edler, S. Kappaun, T. Griesser, Low migration type I photoinitiators for biocompatible thiol-ene formulations, Eur. Polym. J. (2017). doi:10.1016/j.eurpolymj.2016.10.040.

[20] J.R.C. Dizon, A.H. Espera, Q. Chen, R.C. Advincula, Mechanical characterization of 3D-printed polymers, Addit. Manuf. (2018). doi:10.1016/j.addma.2017.12.002.

[21] J.A. Smith, E. Mele, R.P. Rimington, A.J. Capel, M.P. Lewis, V. V. Silberschmidt, S. Li, Polydimethylsiloxane and poly(ether) ether ketone functionally graded composites for biomedical applications, J. Mech. Behav. Biomed. Mater. (2019). doi:10.1016/j.jmbbm.2019.02.012.

[22] L.J. Gerhardt, C.W. Manke, E. Gulari, Rheology of polydimethylsiloxane swollen with supercritical carbon dioxide, J. Polym. Sci. Part B Polym. Phys. (1997). doi:10.1002/(SICI)1099-0488(199702)35:3<523::AID-POLB11>3.0.CO;2-J.

[23] M.M. Rueda, M.C. Auscher, R. Fulchiron, T. Périé, G. Martin, P. Sonntag, P. Cassagnau, Rheology and applications of highly filled polymers: A review of current understanding, Prog. Polym. Sci. (2017). doi:10.1016/j.progpolymsci.2016.12.007.

[24] A.J. Poslinski, M.E. Ryan, R.K. Gupta, S.G. Seshadri, F.J. Frechette, Rheological Behaviour of Filled Polymeric Systems I. Yield Stress and Shear-Thinning Effects, J. Rheol. (N. Y. N. Y). (1988). doi:10.1122/1.549987.

[25] S.S. Sternstein, A.J. Zhu, Reinforcement mechanism of nanofilled polymer melts as elucidated by nonlinear viscoelastic behaviour, Macromolecules. (2002). 
[26] N.C. Paxton, J. Ren, M.J. Ainsworth, A.K. Solanki, J.R. Jones, M.C. Allenby, M.M. Stevens, M.A. Woodruff, Rheological Characterization of Biomaterials Directs Additive Manufacturing of Strontium-Substituted Bioactive Glass/Polycaprolactone Microfibers, Macromol. Rapid Commun. (2019). doi:10.1002/marc.201900019.

[27] R.P. Chhabra, Non-Newtonian fluids: An introduction, in: Rheol. Complex Fluids, 2010. doi:10.1007/978-1-4419-6494-6_1.

[28] L. Medina-Torres, E. Brito-De La Fuente, B. Torrestiana-Sanchez, R. Katthain, Rheological properties of the mucilage gum (Opuntia ficus indica), Food Hydrocoll. (2000). doi:10.1016/S0268-005X(00)00015-1.

[29] V. Arrighi, J.S. Higgins, A.N. Burgess, G. Floudas, Local dynamics of poly(dimethyl siloxane) in the presence of reinforcing filler particles, Polymer (Guildf). (1998). doi:10.1016/S0032-3861(98)00139-6.

[30] Y. Song, Q. Zheng, Linear viscoelasticity of polymer melts filled with nano-sized fillers, Polymer (Guildf). (2010). doi:10.1016/j.polymer.2010.05.018.

[31] D.B. Genovese, Shear rheology of hard-sphere, dispersed, and aggregated suspensions, and filler-matrix composites, Adv. Colloid Interface Sci. (2012). doi:10.1016/j.cis.2011.12.005.

[32] H.A. Barnes, A handbook of elementary rheology, 2000. doi:10.1126/science.1201543.

[33] A. Beigbeder, M. Linares, M. Devalckenaere, P. Degée, M. Claes, D. Beljonne, R. Lazzaroni, P. Dubois, $\mathrm{CH}-\pi$ interactions as the driving force for silicone-based nanocomposites with exceptional properties, Adv. Mater. (2008). doi:10.1002/adma.200701497.

[34] M. Hosokawa, K. Nogi, M. Naito, T. Yokoyama, Nanoparticle Technology Handbook, 2012. doi:10.1016/C2010-0-69564-2. 
[35] H.A. Barnes, A REVIEW OF THE RHEOLOGY OF FILLED VISCOELASTIC SYSTEMS, Rheol. Rev. (2003). doi:10.1081/ASR-120017479.

[36] L. Li, T. Masuda, Effect of dispersion of particles on viscoelasticity of CaCo3-filled polypropylene melts, Polym. Eng. Sci. (1990). doi:10.1002/pen.760301407.

[37] C. Duty, C. Ajinjeru, V. Kishore, B. Compton, N. Hmeidat, X. Chen, P. Liu, A.A. Hassen, J. Lindahl, V. Kunc, What makes a material printable? A viscoelastic model for extrusion-based 3D printing of polymers, J. Manuf. Process. (2018). doi:10.1016/j.jmapro.2018.08.008.

[38] H.A. Barnes, Thixotropy - A review, J. Nonnewton. Fluid Mech. (1997). doi:10.1016/S0377-0257(97)00004-9.

[39] J. Mewis, N.J. Wagner, Thixotropy, Adv. Colloid Interface Sci. (2009). doi:10.1016/j.cis.2008.09.005.

[40] B. Panda, M.J. Tan, Experimental study on mix proportion and fresh properties of fly ash based geopolymer for 3D concrete printing, Ceram. Int. (2018). doi:10.1016/j.ceramint.2018.03.031.

[41] H. Li, Y.J. Tan, K.F. Leong, L. Li, 3D Bioprinting of Highly Thixotropic Alginate/Methylcellulose Hydrogel with Strong Interface Bonding, ACS Appl. Mater. Interfaces. (2017). doi:10.1021/acsami.7b04216.

[42] V.S. Rudraraju, C.M. Wyandt, Rheology of Microcrystalline Cellulose and Sodiumcarboxymethyl Cellulose hydrogels using a controlled stress rheometer: Part II, Int. J. Pharm. (2005). doi:10.1016/j.ijpharm.2004.10.012.

[43] P. Somasundaran, Encyclopedia of surface and colloid science, 2006.

[44] E. Behzadfar, M.H. Abdolrasouli, F. Sharif, H. Nazockdast, Effect of solid loading and aggregate size on the rheological behaviour of pdms/calcium carbonate suspensions, Brazilian J. Chem. Eng. (2009). doi:10.1590/S0104-66322009000400010. 
[45] Y. Wang, M.J. Yu, Effect of volume loading and surface treatment on the thixotropic behaviour of polypropylene filled with calcium carbonate, Polym. Compos. (2000). doi:10.1002/pc.10159.

[46] Y. Jin, C. Liu, W. Chai, A. Compaan, Y. Huang, Self-Supporting Nanoclay as Internal Scaffold Material for Direct Printing of Soft Hydrogel Composite Structures in Air, ACS Appl. Mater. Interfaces. (2017). doi:10.1021/acsami.7b03613.

[47] J.A. Smith, E. Mele, R.P. Rimington, A.J. Capel, M.P. Lewis, V.V. Silberschmidt, S. Li, Polydimethylsiloxane and poly(ether) ether ketone functionally graded composites for biomedical applications, J. Mech. Behav. Biomed. Mater. 93 (2019). doi:10.1016/j.jmbbm.2019.02.012.

[48] G. Akovali, Advances in Polymer Coated Textiles, Adv. Polym. Coat. Text. (2012).

[49] F. Chambon, H.H. Winter, Linear Viscoelasticity at the Gel Point of a Crosslinking PDMS with Imbalanced Stoichiometry, J. Rheol. (N. Y. N. Y). (1987). doi:10.1122/1.549955.

[50] E.J. Wong, Modeling and Control of Rapid Cure in Polydimethylsiloxane (PDMS) for Microfluidic Device Applications in Partial Fulfillment of the Requirements for the Degree of Doctor of Philosophy in Mechanical Engineering, (2010) 1-151.

[51] Avantor, MED-4930 LIQUID SILICONE RUBBER, (2019). https://nusil.com/product/med-4930_liquid-silicone-rubber.

[52] J.B. Grande, A.S. Fawcett, A.J. McLaughlin, F. Gonzaga, T.P. Bender, M.A. Brook, Anhydrous formation of foamed silicone elastomers using the Piers-Rubinsztajn reaction, Polymer (Guildf). (2012). doi:10.1016/j.polymer.2012.05.033.

[53] D. Zhu, S. Handschuh-Wang, X. Zhou, Recent progress in fabrication and application of polydimethylsiloxane sponges, J. Mater. Chem. A. (2017). doi:10.1039/c7ta04577h.

[54] A.M. Kraynik, Foam structure: From soap froth to solid foams, MRS Bull. (2003). 
doi:10.1557/mrs2003.80.

[55] H. So, A.S. Fawcett, H. Sheardown, M.A. Brook, Surface-active copolymer formation stabilizes PEG droplets and bubbles in silicone foams, J. Colloid Interface Sci. (2013). doi:10.1016/j.jcis.2012.09.017.

[56] M. Liu, J. Sun, Q. Chen, Influences of heating temperature on mechanical properties of polydimethylsiloxane, Sensors Actuators, A Phys. 151 (2009) 42-45. doi:10.1016/j.sna.2009.02.016.

[57] J. González-Rivera, R. Iglio, G. Barillaro, C. Duce, M.R. Tinè, Structural and thermoanalytical characterization of 3D porous PDMS foam materials: The effect of impurities derived from a sugar templating process, Polymers (Basel). (2018). doi:10.3390/polym10060616.

[58] C. Camino, S.M. Lomakin, M. Lazzari, Polydimethylsiloxane thermal degradation part 1. Kinetic aspects, Polymer (Guildf). (2001). doi:10.1016/S0032-3861(00)00652-2.

[59] M.M. Hatamleh, D.C. Watts, Mechanical properties and bonding of maxillofacial silicone elastomers, Dent. Mater. (2010). doi:10.1016/j.dental.2009.10.001.

[60] N. Krueger, S. Luebberding, M. Oltmer, M. Streker, M. Kerscher, Age-related changes in skin mechanical properties: A quantitative evaluation of 120 female subjects, Ski. Res. Technol. (2011). doi:10.1111/j.1600-0846.2010.00486.x.

[61] J. Bijwe, S. Sen, A. Ghosh, Influence of PTFE content in PEEK-PTFE blends on mechanical properties and tribo-performance in various wear modes, Wear. (2005). doi:10.1016/j.wear.2004.10.008.

[62] A. Ahmed, S. Irhayyim, H. Hammood, Effect of Yttrium Oxide Particles on the Mechanical Properties of Polymer Matrix Composite, in: Int. Conf. Mater. Eng. Sci., 2018: pp. 1-9.

[63] R. Periyasamy, S. Anand, A.C. Ammini, The effect of aging on the hardness of foot sole 
skin: A preliminary study, Foot. (2012). doi:10.1016/j.foot.2012.01.003.

[64] I.D. Johnston, D.K. McCluskey, C.K.L. Tan, M.C. Tracey, Mechanical characterization of bulk Sylgard 184 for microfluidics and microengineering, J. Micromechanics Microengineering. 24 (2014) 035017. doi:10.1088/0960-1317/24/3/035017.

[65] M.M. Caruso, D.A. Davis, Q. Shen, S.A. Odom, N.R. Sottos, S.R. White, J.S. Moore, Mechanically-induced chemical changes in polymeric materials, Chem. Rev. (2009). doi:10.1021/cr9001353.

[66] D.E. Hanson, M. Hawley, R. Houlton, K. Chitanvis, P. Rae, E.B. Orler, D.A. Wrobleski, Stress softening experiments in silica-filled polydimethylsiloxane provide insight into a mechanism for the Mullins effect, Polymer (Guildf). 46 (2005) 10989-10995. doi:10.1016/j.polymer.2005.09.039.

[67] S. Gagliardi, V. Arrighi, R. Ferguson, M.T.F. Telling, Restricted dynamics in polymerfiller systems, in: Phys. B Condens. Matter, 2001. doi:10.1016/S0921-4526(01)005208.

[68] M.A. Osman, A. Atallah, M. Müller, U.W. Suter, Reinforcement of poly(dimethylsiloxane) networks by mica flakes, Polymer (Guildf). 42 (2001) 65456556. doi:10.1016/S0032-3861(01)00128-8.

[69] K. Tian, J. Bae, S.E. Bakarich, C. Yang, R.D. Gately, G.M. Spinks, M. in het Panhuis, Z. Suo, J.J. Vlassak, 3D Printing of Transparent and Conductive Heterogeneous Hydrogel-Elastomer Systems, Adv. Mater. (2017). doi:10.1002/adma.201604827.

[70] J. Plott, X. Tian, A.J. Shih, Voids and tensile properties in extrusion-based additive manufacturing of moisture-cured silicone elastomer, Addit. Manuf. (2018). doi:10.1016/j.addma.2018.06.010.

[71] G.H. Loh, E. Pei, D. Harrison, M.D. Monzón, An overview of functionally graded additive manufacturing, Addit. Manuf. (2018). doi:10.1016/j.addma.2018.06.023. 
1 [72] R.M. Mahamood, E.T.A. Member, M. Shukla, S. Pityana, Functionally Graded Material : An Overview, World Congr. Eng. III (2012) 2-6.

3 [73] L. Ren, Z. Song, H. Liu, Q. Han, C. Zhao, B. Derby, Q. Liu, L. Ren, 3D printing of materials with spatially non-linearly varying properties, Mater. Des. (2018). doi:10.1016/j.matdes.2018.07.012.

[74] J.R.C. Dizon, A.H. Espera, Q. Chen, R.C. Advincula, Mechanical characterization of 3D-printed polymers, Addit. Manuf. $20 \quad$ (2018) 44-67. doi:10.1016/j.addma.2017.12.002.

[75] D. Kazmer, Three-Dimensional Printing of Plastics, in: Appl. Plast. Eng. Handb. Process. Mater. Appl. Second Ed., 2017. doi:10.1016/B978-0-323-39040-8.00029-8.

[76] M. Afshar, A.P. Anaraki, H. Montazerian, J. Kadkhodapour, Additive manufacturing and mechanical characterization of graded porosity scaffolds designed based on triply periodic minimal surface architectures, J. Mech. Behav. Biomed. Mater. (2016). doi:10.1016/j.jmbbm.2016.05.027.

[77] S.E. Bakarich, R. Gorkin, R. Gately, S. Naficy, M. in het Panhuis, G.M. Spinks, 3D printing of tough hydrogel composites with spatially varying materials properties, Addit. Manuf. (2017). doi:10.1016/j.addma.2016.12.003.

[78] L. Bokobza, O. Rapoport, Reinforcement of natural rubber, J. Appl. Polym. Sci. (2002). doi:10.1002/app.10858.

[79] F. Pirmoradi, L. Cheng, M. Chiao, A magnetic poly(dimethylesiloxane) composite membrane incorporated with uniformly dispersed, coated iron oxide nanoparticles, J. Micromechanics Microengineering. (2010). doi:10.1088/0960-1317/20/1/015032. 
